\title{
Preparation and Characterization of PEG-PLA Genistein Micelles Using a Modified Emulsion-Evaporation Method
}

\author{
Qiuchen Cheng, ${ }^{1,2}$ Wen Qin $\left(\mathbb{D},,^{3,2}\right.$ Yanhong Yu $\mathbb{D},{ }^{1}$ Guojian Li $\mathbb{D},{ }^{1}$ Jizhou Wu $\left(\mathbb{D},{ }^{1}\right.$ \\ and Lang Zhuo iD ${ }^{4}$ \\ ${ }^{1}$ Department of Infectious Diseases, First Affiliated Hospital of Guangxi Medical University, No. 6 Shuangyong Road, Nanning, \\ Guangxi 530021, China \\ ${ }^{2}$ Guangxi Botanical Garden of Medicinal Plants, No. 189 Changgang Road, Nanning, Guangxi 530021, China \\ ${ }^{3}$ College of Chemistry and Chemical Engineering, Guangxi University, 100 Daxue East Road, Nanning, 530004 Guangxi, China \\ ${ }^{4}$ Guangxi Medical University, No. 22 Shuangyong Road, Nanning, Guangxi 530021, China
}

Correspondence should be addressed to Guojian Li; liguojian2016@yeah.net and Lang Zhuo; zhuolang@yahoo.com

Received 9 June 2020; Revised 1 October 2020; Accepted 15 October 2020; Published 2 November 2020

Academic Editor: Mohamed Bououdina

Copyright $\odot 2020$ Qiuchen Cheng et al. This is an open access article distributed under the Creative Commons Attribution License, which permits unrestricted use, distribution, and reproduction in any medium, provided the original work is properly cited.

\begin{abstract}
The objective of this study is to improve the bioavailability of genistein by encapsulation with polyethylene glycol-polylactic acid (PEG-PLA) copolymers. Genistein micelles (GMs) prepared using a modified emulsion-evaporation method were more stable than those made with the original method. The effect of polyvinyl alcohol, Tween 80, sonication time, PEG-PLA/genistein ratio, and organic phase (acetone) $/ \mathrm{H}_{2} \mathrm{O}$ ratio on the size, polydispersity index, encapsulation efficiency, and drug loading efficiency of GMs was investigated. GMs were obtained and characterized under optimal experimental conditions. For long-term storage, GMs were lyophilized by freeze drying with trehalose to produce genistein lyophilized powder (GLP). The analysis of GLP by Fourier-transform infrared spectroscopy and differential scanning calorimetry showed that genistein was successfully incorporated into the micellar structure. In vitro release experiments revealed that the incorporation of genistein into PEG-PLA copolymers significantly improved its solubility and bioavailability. GLP was more potent in inhibiting the proliferation of HSCT6 cells than genistein. Treatment with GLP at $10-20 \mu \mathrm{g} / \mathrm{mL}$ for $48 \mathrm{~h}$ significantly inhibited the protein expression of $\alpha$-smooth muscle actin and collagen I in HSC-T6 cells compared with the control. These data demonstrated that the improved solubility and bioavailability of genistein in the form of GLP enhanced its antifibrotic effect in vitro.
\end{abstract}

\section{Introduction}

Genistein $\left(4^{\prime}, 5,7\right.$-trihydroxyisoflavone; Figure 1$)$ is a phytoestrogen found in several plants, including soybean, peanut, the roots of Subprostrate sophora, and pods of the pagoda tree Sophora japonica Linn. The beneficial effects of this compound include antioxidation, cell cycle arrest, induction of apoptosis, and inhibition of both angiogenesis and cancer metastasis [1, 2]. Genistein can maintain its antioxidant activity at $70^{\circ} \mathrm{C}$ and $\mathrm{pH} 7.0$ for over 20 days [3] and modulates multiple signaling pathways, including Nrf2, MAPK, and NF- $\kappa \mathrm{B}$ [4-6]. Genistein is highly soluble in ethanol, methanol, and dimethyl sulfoxide, but poorly soluble in water $(1.43 \mu \mathrm{g} / \mathrm{mL})$, which is the main cause of the low bio- availability of this compound, limiting its potential therapeutic use [7-10].

Nanotechnology has allowed incorporating new pharmaceuticals into different types of nanoparticles (liposomes and emulsions) and improving drug properties, particularly solubility and bioavailability [11-15]. Nanoparticles are prepared using a variety of polymers, including hydrophilic polyethylene glycol (PEG), hydrophobic polylactic acid (PLA), and amphiphilic PEG-PLA block copolymers [16]. Several copolymers have been used as nanoparticle carriers. For instance, aqueous-core PEG-coated PLA was used to entrap gemcitabine hydrochloride, PLA-PEG-PLA with lisinopril was synthesized in the presence of dicyclohexylcarbodiimide and dimethylaminopyridine, and micelles with different PLA : 
<smiles>O=c1c(-c2ccc(O)cc2)coc2cc(O)cc(O)c12</smiles>

Figure 1: Chemical structure of genistein.

PEG ratios are used as carriers of hydrophobic drugs [17-21]. PLA-PEG is reported to be safe for humans [22] and has been shown to improve the bioavailability and maintain the anticancer properties of curcumin [23]. Furthermore, PEG-PLA promotes the sustained release of recombinant human growth hormone for more than 1 month [24]. PEG is widely used in pharmacological applications [25].

We previously reported that genistein attenuated the activation of hepatic stellate cells (HSCs) induced by fibrogenic cytokines [26]. Liver fibrosis progression is associated with HSC activation, number of activated HSCs, and abnormal production of extracellular matrix proteins. Therefore, inhibiting HSCs is a therapeutic strategy for managing liver fibrosis [27, 28].

This study evaluated the effect of genistein micelles (GMs) produced with PEG-PLA on the solubility and bioavailability of hydrophobic genistein molecules and assessed the ability of GMs to inhibit the activation of HSCs in vitro. Preliminary data showed that encapsulated genistein had better bioavailability and a higher antifibrotic effect in cultured cells.

\section{Material and Methods}

2.1. Materials. PEG-PLA block copolymers (PEG 5\% (Mw of 5000) and PLA 95\% (Mw of 45000)) were synthesized by Xi'an Ruixi Biomaterial Co. Ltd. (Xi'an, China). Genistein (98.25\%) was supplied by Nanjing Zelang Biotechnology Co. Ltd. (Nanjing, China). Microporous membranes $(0.8 \mu \mathrm{m})$ were purchased from Tianjin Jinteng Experiment Equipment Co. Ltd. (Tianjin, China). Dialysis bags (8000-12000 kDa) were purchased from Beijing Solarbio Science \& Technology Co. Ltd. (Beijing, China). Polyvinyl alcohol (PVA) 1799 (Mw of 75514) was purchased from Chengdu Kelong Chemical Co. Ltd. (Chengdu, China). All commercial chemicals and reagents were of analytical grade (purity $>98 \%$ ).

2.2. Preparation of GMs. GMs were prepared using two methods. In the original emulsion-evaporation method [17, 18, 29, 30], PEG-PLA, genistein, and Tween 80 were dissolved in acetone, and the solution was mixed with 0$15 \mathrm{mg} / \mathrm{mL}$ PVA solution or double-distilled water (DDW) and stirred at $800 \mathrm{rpm}$. The mixture was sonicated using an ultrasonic cell disruptor on ice for $0,4,8,16$, or $24 \mathrm{~min}$. Acetone was removed by evaporation with magnetic stirring for $8 \mathrm{~h}$ at room temperature to obtain GMs.

In the modified method, the mixture was autoclaved at $121^{\circ} \mathrm{C}$ for $20 \mathrm{~min}$. Nonencapsulated genistein was removed by filtration through $0.8 \mu \mathrm{m}$ nitrocellulose membranes. GMs were found in the filtrate. Blank micelles (BMs) were prepared under the same experimental conditions in the absence of genistein. The emulsions were lyophilized in a vacuum freeze drier (LGJ-10E, Beijing Sihuan Scientific Instrument Factory) using trehalose as cryoprotectant. Briefly, $10 \%$ trehalose was added and dissolved in GMs or BMs after prefreezing overnight at $-60^{\circ} \mathrm{C}$ and freeze drying for $8 \mathrm{~h}$, and GLP and blank lyophilized powder (BLP, blank micelles after freeze drying) were obtained. Micelles without trehalose were prepared under the same experimental conditions and were used as a control.

2.3. Characterization of GMs. The stability of GMs prepared using the two emulsion-evaporation methods was analyzed after storage at $4^{\circ} \mathrm{C}$ for 7 days.

The size and zeta potential of GMs were measured in three independent experiments on a Zetasizer Nano ZS90 (Malvern Instruments, Malvern, UK) at room temperature using $1 \mathrm{~mL}$ of each emulsion, according to the manufacturer's instructions.

The morphology of GMs was analyzed by transmission electron microscopy (TEM) (HITACHI H-500, Tokyo). Briefly, the samples were added to carbon-coated copper grids and examined at an acceleration voltage of $100 \mathrm{kV}$.

The weight of genistein in micelles was determined by high-performance liquid chromatography (HPLC) (Agilent 1260, USA). The total amount of genistein in the system (free and encapsulated) was quantified using the following method: GMs were dissolved in DDW, diluted in methanol, and filtered through $0.22 \mu \mathrm{m}$ nitrocellulose membranes. Genistein $(10 \mu \mathrm{L})$ was separated on a Syncronis $\mathrm{C}_{18}$ column $(5 \mu \mathrm{m}, 4.6$ $\mathrm{mm} \times 250 \mathrm{~mm}$, Thermo Fisher Scientific, Waltham, MA, USA) guarded with a precolumn at $30^{\circ} \mathrm{C}$, at a flow rate of $1.0 \mathrm{~mL} / \mathrm{min}$, and UV detection at $262 \mathrm{~nm}$. The mobile phase consisted of $0.1 \%$ phosphoric acid in $70 \%$ methanol [31]. The encapsulation efficiency (EE) and drug loading efficiency (DLE) were calculated using the following formulas:

$$
\begin{gathered}
\operatorname{EE}(\%)=\frac{m_{1}}{m_{0}} \times 100 \%, \\
\operatorname{DLE}(\%)=\frac{m_{1}}{m_{2}+m_{0}} \times 100 \%,
\end{gathered}
$$

where $m_{0}$ is the weight of total genistein, $m_{1}$ is the weight of genistein in GMs, and $m_{2}$ is the weight of PEG-PLA.

2.4. Characterization of Genistein Lyophilized Powder (GLP). GLP samples previously lyophilized from $2 \mathrm{~mL}$ of GMs were dissolved in $2 \mathrm{~mL}$ of DDW.

The size and zeta potential of GLP were measured in three independent experiments on a Zetasizer Nano ZS90 (Malvern Instruments, Malvern, UK) at room temperature using $1 \mathrm{~mL}$ of each emulsion, according to the manufacturer's instructions [32].

The morphology of GMs was analyzed by TEM (HITACHI, H-500, Tokyo). The samples were added to carboncoated copper grids and examined at an acceleration voltage of $100 \mathrm{kV}$.

The solubility of GLP was measured in six dilutions. A volume of $0.2,0.3,0.4,0.5,1.0$, or $2.0 \mathrm{~mL}$ of DDW was added 
to each of the six GLP samples, respectively, previously lyophilized from $2 \mathrm{~mL}$ of GMs.

The structure of genistein, GLP, BLP, and genistein+BLP was examined by Fourier-transform infrared spectroscopy (FTIR) (Nicolet, NEXUS470, USA) using $\mathrm{KBr}$ pellets in the wavelength range of 400 to $4000 \mathrm{~cm}^{-1}$ at a resolution of $4 \mathrm{~cm}^{-1}$.

The thermal analysis of genistein, GLP, and BLP was performed by differential scanning calorimetry (DSC) (PerkinElmer, DSC6200, USA). Samples were hermetically sealed in an aluminum pan under nitrogen at a heating rate of $10^{\circ} \mathrm{C} / \mathrm{min}$ and a temperature range of $25^{\circ} \mathrm{C}$ to $600^{\circ} \mathrm{C}$.

2.5. In Vitro Release Study. A suitable medium for the in vitro release of genistein was selected using the shake-flask method. The release of genistein from GLP was evaluated using dialysis bags (MWCO of $8000-12000 \mathrm{kDa}$ ) [3]. Briefly, $1875 \mathrm{mg}$ of GLP (containing $1.5 \mathrm{mg}$ of genistein) or $1.5 \mathrm{mg}$ of free genistein (control sample) was added to $15 \mathrm{~mL}$ of DDW and dialyzed in $150 \mathrm{~mL}$ of PBS containing Tween 80 $(2.75 \mathrm{mg} / \mathrm{mL})$ under stirring at $100 \mathrm{rpm}$ and $37^{\circ} \mathrm{C}$ in an incubator shaker (Crystal, IS-RDD3, USA). At $5 \mathrm{~min}$, $15 \mathrm{~min}, 30 \mathrm{~min}, 1 \mathrm{~h}, 2 \mathrm{~h}, 5 \mathrm{~h}, 8 \mathrm{~h}, 24 \mathrm{~h}, 48 \mathrm{~h}$, and $72 \mathrm{~h}, 1 \mathrm{~mL}$ of dialysis medium was collected, and the volume was replaced with fresh medium. Genistein in the eluate was purified by filtration through $0.22 \mu \mathrm{m}$ nitrocellulose membranes and quantified by HPLC.

2.6. Cell Culture and Treatment. The immortalized rat hepatic stellate cell line HSC-T6 (KCB 200703YJ) was purchased from the Chinese Academy of Science (Kunming, China). Cells were cultured in Dulbecco's modified Eagle's medium supplemented with $10 \%$ fetal bovine serum and $1 \%$ penicillin/streptomycin (Gibco, USA). Cultures were incubated in an atmosphere of $5 \% \mathrm{CO}_{2}$ at $37^{\circ} \mathrm{C}$. BLP and GLP were dissolved in $2 \mathrm{~mL}$ of complete growth medium at a concentration of $80 \mu \mathrm{g} / \mathrm{mL}$. Genistein was dissolved in dimethyl sulfoxide (DMSO) to yield a stock solution of $5 \mathrm{mg} / \mathrm{mL}$ and further diluted in complete medium. The DMSO concentration in the assay was less than $0.1 \%$.

2.7. Measurement of Cell Toxicity Using the MTT Assay. The viability of HSC-T6 cells was assessed using the MTT proliferation assay, as described previously [33]. For this purpose, $1 \times$ $10^{4}$ cells in $100 \mu \mathrm{L}$ of culture medium were seeded in each well of a 96-well culture plate, incubated in a $\mathrm{CO}_{2}$ incubator at $37^{\circ} \mathrm{C}$ overnight, and treated with different concentrations of BLP, genistein, or GLP $(0.3125,0.625,1.25,2.5,5,10,20,40$, and $80 \mu \mathrm{g} / \mathrm{mL}$ ) for 24,48 , and $72 \mathrm{~h}$. Each treatment was performed in quadruplicate. After that, $20 \mu \mathrm{L}$ of 3-(4,5-dimethylthiazol-2yl)-2,5-diphenyltetrazolium bromide (MTT, Solarbio, China) solution $(5 \mathrm{mg} / \mathrm{mL})$ was added per well, and the plates were incubated for $4 \mathrm{~h}$ at $37^{\circ} \mathrm{C}$. The supernatants were discarded, and blue formazan crystals were dissolved in $200 \mu \mathrm{L}$ of DMSO (FUYU, Tianjin, China) in each well and stirred for $10 \mathrm{~min}$ at room temperature. The optical density was read at $570 \mathrm{~nm}$ in a microplate reader (Tecan, Switzerland) using DMSO as a blank. The experiments were repeated independently three times.
2.8. RNA Extraction and Semiquantitative PCR. HSC-T6 cells $\left(8 \times 10^{4} /\right.$ well $)$ were seeded onto 6 -well plates for $16 \mathrm{~h}$ until they reached $50 \%$ confluence. The antifibrotic activity of BLP, genistein, and GLP was assessed by PCR and Western blotting. Cells were treated with four concentrations of each nanoparticle $(0,5$, 10 , and $20 \mu \mathrm{g} / \mathrm{mL}$ ) for $48 \mathrm{~h}$ and analyzed for viability.

Total mRNA was extracted using the RNeasy Mini Kit (Takara, Japan). All RNA samples were treated with gDNA Eraser (Takara, Japan) to remove residual genomic DNA contamination before the reverse transcription of total RNA to cDNA. Reverse transcription was performed using the PrimeScript RT reagent Kit (Takara, Japan) as per the manufacturer's instructions. Semiquantitative PCR was performed in a thermal cycler (German Biometra) in $25 \mu \mathrm{L}$ reactions containing $1 \mu \mathrm{L}$ of $\mathrm{cDNA}, 1 \mu \mathrm{L}$ of forward and reverse primers $(10 \mu \mathrm{mol} / \mathrm{L}), 12.5 \mu \mathrm{L}$ of Green Taq Mix (Takara, Japan), and $10.5 \mu \mathrm{L}$ of RNase-free $\mathrm{H}_{2} \mathrm{O}$. The amplification conditions consisted of an initial denaturation step at $95^{\circ} \mathrm{C}$ for $5 \mathrm{~min}$, followed by 30 amplification cycles $\left(95^{\circ} \mathrm{C}\right.$ for $15 \mathrm{~s}, 55^{\circ} \mathrm{C}$ for $20 \mathrm{~s}$, and $72^{\circ} \mathrm{C}$ for $30 \mathrm{~s}$ ) and a final extension cycle at $72^{\circ} \mathrm{C}$ for $5 \mathrm{~min}$. The relative intensity of the signals was quantified by densitometric analysis (Bio-Rad, United States). Semiquantitative PCR was performed in triplicate and repeated independently three times, and gene expression was normalized against the housekeeping gene glyceraldehyde-3 phosphate dehydrogenase (GAPDH). The primer sequences are listed in Table 1 . The amplification products were separated on $2 \%$ agarose gels, stained with the GelRed dye, and semiquantified by densitometry using ImageJ software version 1.47.

2.9. Western Blot Analysis. Whole cells were lysed in cold RIPA buffer (Beyotime, China) containing $1 \mathrm{mM}$ phenylmethanesulfonyl fluoride (Solarbio, China) for $30 \mathrm{~min}$ on ice. The lysates were centrifuged at $12000 \mathrm{rpm}$ for $15 \mathrm{~min}$ at $4{ }^{\circ} \mathrm{C}$, and the supernatant was quantified using the Pierce bicinchoninic acid (BCA) protein assay kit (Takara, Japan). All samples were mixed with $4 \times$ loading buffer (Solarbio, China), heated in a boiling water bath for $5 \mathrm{~min}$, and stored at $-80^{\circ} \mathrm{C}$ until use. Thirty micrograms of proteins was separated on a $12 \%$ SDSpolyacrylamide gel and transferred to polyvinylidene fluoride membranes (Millipore, Billerica, USA). The membranes were blocked with $5 \%$ skim milk in Tris-buffered saline and Tween 20 (TBST) (10 mM Tris- $\mathrm{HCl}, 150 \mathrm{mM} \mathrm{NaCl}, 0.1 \%$ Tween 20 , and $\mathrm{pH}$ 7.5) at room temperature for $1 \mathrm{~h}$ and incubated with primary antibodies overnight at $4^{\circ} \mathrm{C}$. The membranes were washed with TBST and incubated with a secondary antibody for $1 \mathrm{~h}$ at room temperature. After that, the membranes were washed with TBST six times for $5 \mathrm{~min}$, and proteins were visualized with the SuperSignal West Pico Chemiluminescence Kit (Thermo Scientific, USA) and quantified with ImageJ software using GAPDH as a control. The antibodies used were anti- $\alpha$ smooth muscle actin ( $\alpha$-SMA) $(1: 1000$, Abcam, USA), antiGAPDH (1:1000, ZSGB-BIO, China), HRP-conjugated goat anti-rabbit IgG, and goat anti-mouse IgG (1:5000, ZSGB$\mathrm{BIO}$, China).

2.10. Statistical Analysis. The results were expressed as mean \pm SEM. Data were processed using Origin software version 8.0. Statistical analysis was performed using one-way 
TABLE 1: Gene primers used in semiquantitative PCR.

\begin{tabular}{|c|c|c|}
\hline Genes & Nucleotide sequence $\left(5^{\prime}-3^{\prime}\right)$ & $\begin{array}{l}\text { Product size } \\
\quad \text { (bp) }\end{array}$ \\
\hline \multirow{2}{*}{ GAPDH } & $\begin{array}{l}\text { GACATGCCGCCTGGAGAAAC } \\
\text { (forward) }\end{array}$ & \multirow{2}{*}{181} \\
\hline & $\begin{array}{c}\text { AGCCCAGGATGCCCTTTAGT } \\
\text { (reverse) }\end{array}$ & \\
\hline \multirow{2}{*}{$\alpha$-SMA } & $\begin{array}{l}\text { CAGGGAGTGATGGTTGGAAT } \\
\text { (forward) }\end{array}$ & \multirow{2}{*}{108} \\
\hline & $\begin{array}{c}\text { GATGATGCCGTGTTCTATCG } \\
\text { (reverse) }\end{array}$ & \\
\hline \multirow{2}{*}{$\begin{array}{l}\text { Collagen } \\
\text { I }\end{array}$} & $\begin{array}{c}\text { ATCTCCTGGTGCTGATGGAC } \\
\text { (forward) }\end{array}$ & \multirow{2}{*}{109} \\
\hline & $\begin{array}{c}\text { GCCTCTTTCTCCTCTCTGACC } \\
\text { (reverse) }\end{array}$ & \\
\hline
\end{tabular}

analysis of variance followed by a multiple comparison test for multiple experimental groups. The level of significance was set at $P<0.05$.

\section{Results}

3.1. Physical Stability of GMs. GMs prepared using the original emulsion-evaporation method contained white precipitates (probably genistein) on day 3 after preparation, and the precipitates were insoluble in water even after stirring for $5 \mathrm{~min}$ (Figure 2(a)). In contrast, GMs made using the modified method (with an autoclave step) presented a blue color due to the Tyndall effect (Figures 2(b) and 2(d)) and were stable for at least 7 days at $4^{\circ} \mathrm{C}$. Therefore, the modified method was selected for subsequent experiments.

Autoclaving is commonly used to sterilize medical devices and pharmaceutical preparations, which are stable at operating conditions (high temperature and pressure). Gellan and hyaluronan nanohydrogels have been prepared using a single step and sterilized by autoclaving [34]. The antibacterial activity of nisin nanoparticles was increased after autoclave treatment, and it is likely that micelles selfassemble under this treatment. In addition, emulsions are more stable under sterile conditions than under nonsterile conditions.

3.2. Synthesis and Characterization of GMs. It was reasonable to assume that the concentration of PVA and Tween 80, sonication time, PEG-PLA/genistein ratio, and organic phase (acetone) $/ \mathrm{H}_{2} \mathrm{O}$ ratio may affect the characteristics of GMs. Therefore, experiments were conducted to investigate the potential effects of individual factors on the formation of micelles and their characteristics, including size, polydispersity index (PDI), EE, and DLE. These assays were conducted to identify optimal conditions for synthesizing micelles with improved characteristics.

PVA at 10 and $15 \mathrm{mg} / \mathrm{mL}$ had a significant influence on the diameter of GMs when compared to the control (without PVA) (Figure 3(a)). The micelle diameter was gradually increased as PVA concentration increased from 0 to $15 \mathrm{mg} / \mathrm{mL}$, suggesting that PVA helped form the PEG-PLA

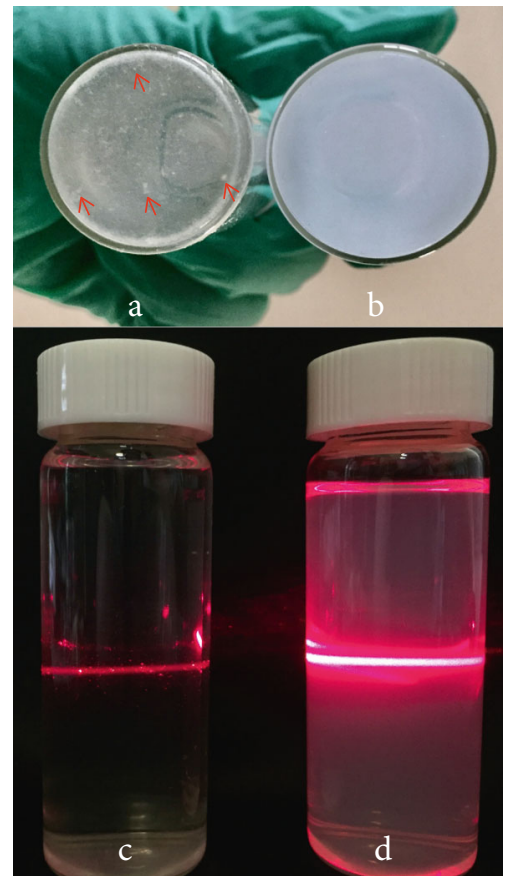

Figure 2: Genistein micelles (GM) subjected to high temperature and pressure remained in suspension (b), whereas GM not subjected to this treatment coalesced and formed a white precipitate (a). GM suspension stability was estimated by the Tyndall effect (c, d).

micellar core and increased its diameter. In contrast, PVA had no significant impact on EE and DLE at this concentration range (Figure 4(a)). Previous studies have shown that $2-10 \%$ PVA can serve as stabilizers during the synthesis of estrogen-containing nanoparticles using an emulsificationdiffusion method $(w / v)$. PVA stabilizes emulsions by adsorbing to their surface [35]. In our study, PVA may have adsorbed to the surface of polymeric micelles. Using the modified emulsion-evaporation method, PVA increased the size of GMs but did not increase EE and DLE; therefore, PVA was not used in the synthesis protocol. PVA may increase the GM diameter being incorporated into the micellar structure.

The GM diameter decreased whereas EE and DLE increased as the concentration of the nonionic surfactant Tween 80 increased (Figures 3(b) and 4(b)). These results agree with previous studies $[36,37]$ and indicate that Tween 80 , which is widely used as a wetting agent, emulsifier, lubricant, and diffusion agent in pharmaceutical excipients, may help form GMs.

Sonication time did not affect GM diameter (Figure 3(c)), which is not consistent with a previous study [38], and did not significantly affect EE and DLE, except at the time point 24 min (Figure 4(c)). The slight decrease in EE at 16 and $24 \mathrm{~min}$ was probably due to drug release from GMs after extended sonication. The concentration of Tween 80 affected the GM diameter more strongly than other factors.

When measured in the narrow range from $16: 8$ to $16: 2$, the PEG-PLA/genistein weight ratio did not seem to alter the GM diameter (Figure 3(d)). However, in this range, the 


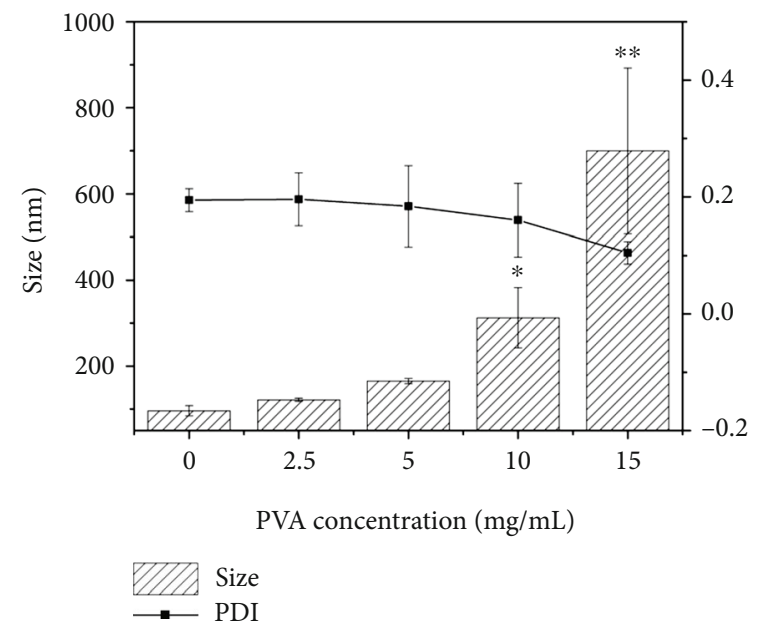

(a)

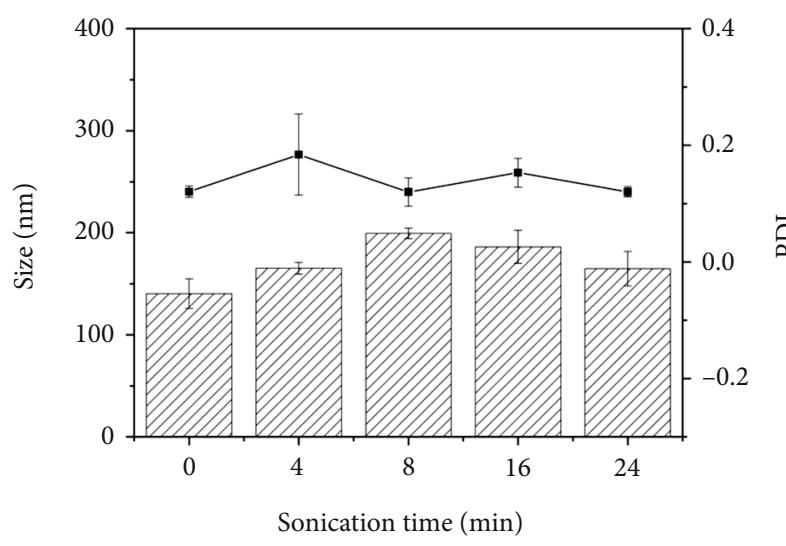

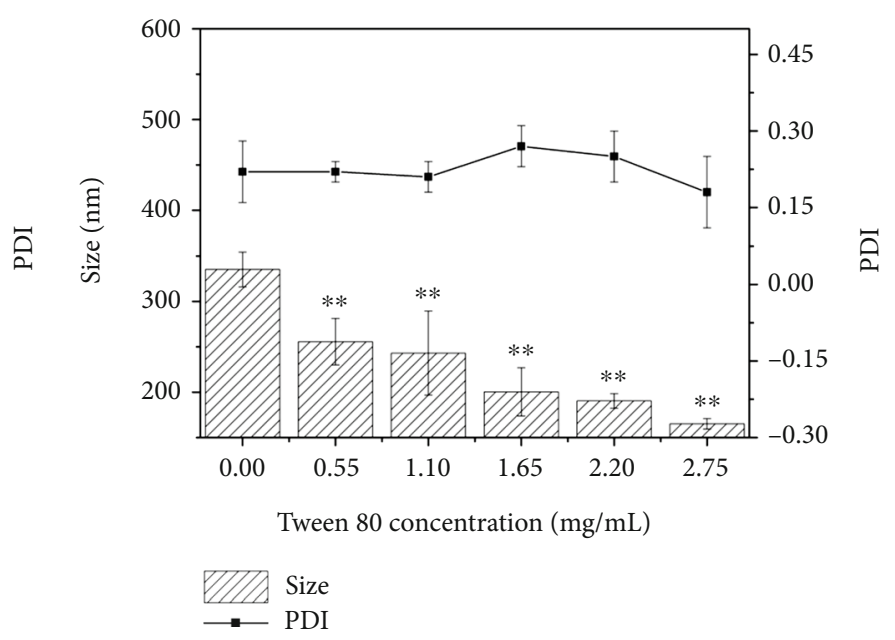

(b)
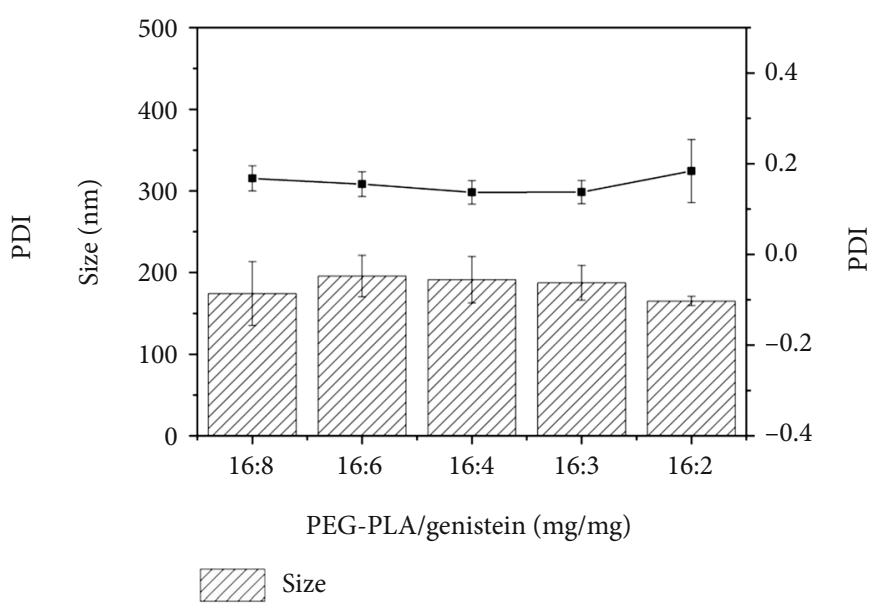

(c)

(d)

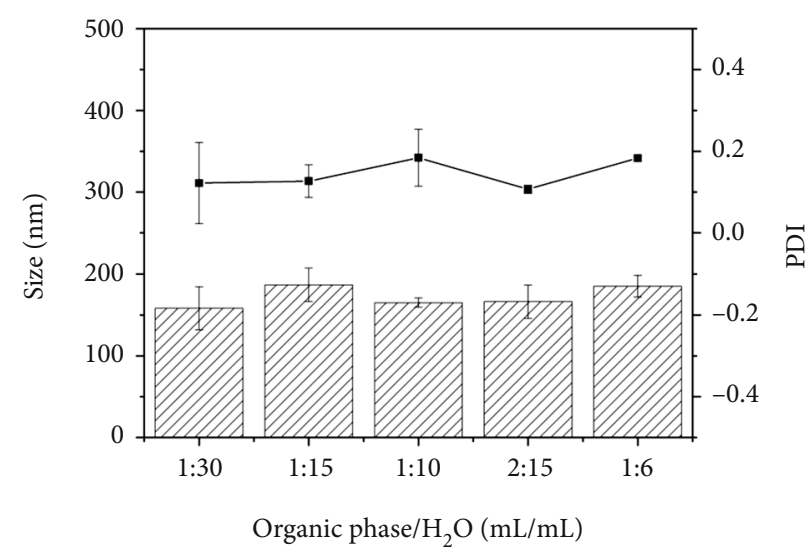

Size

$\longrightarrow$ PDI

(e)

FIGURE 3: Effects of polyvinyl alcohol (PVA) concentration (a), Tween 80 concentration (b), sonication time (c), PEG-PLA/genistein ratio (d), and organic $/ \mathrm{H}_{2} \mathrm{O}$ ratio (e) on the size and polydispersity index (PDI) of genistein micelles $\left(n=3\right.$, mean $\pm \mathrm{SD},{ }^{*} P<0.05,{ }^{* *} P<0.01$ compared with the first time point). 

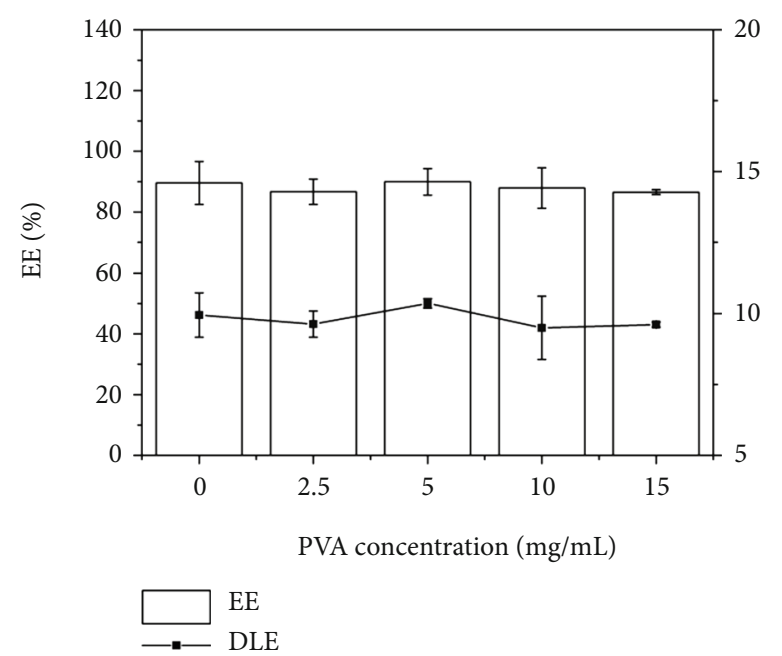

(a)

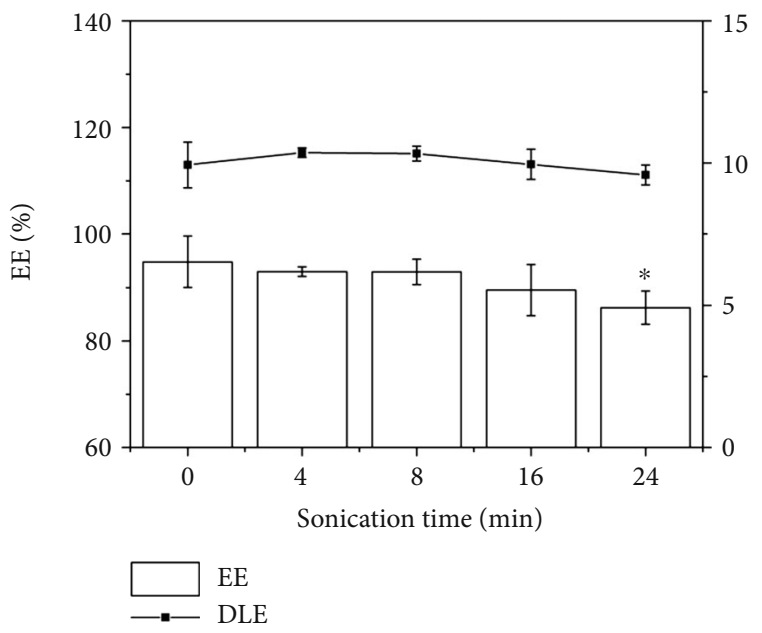

(c)

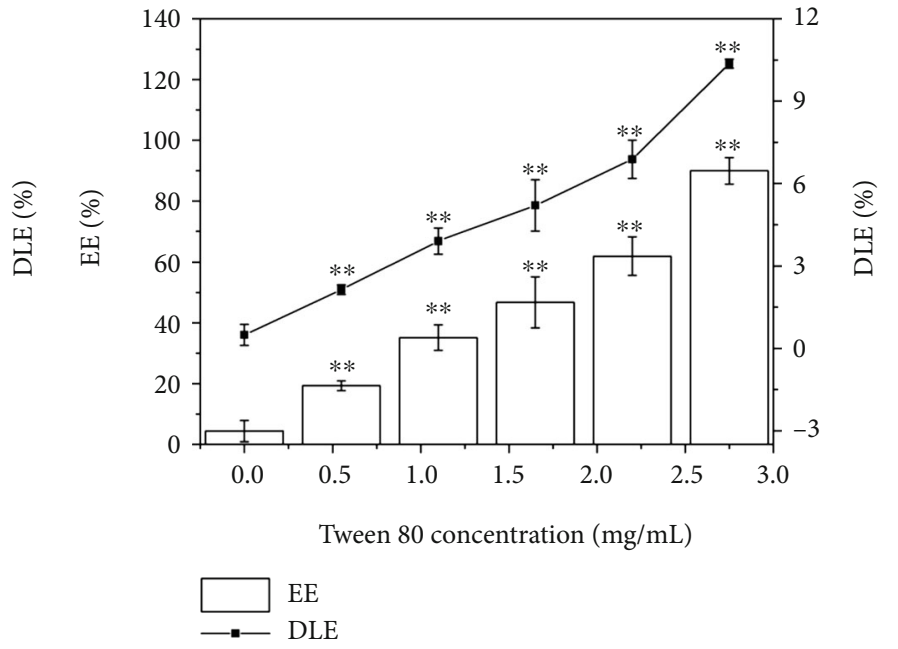

(b)

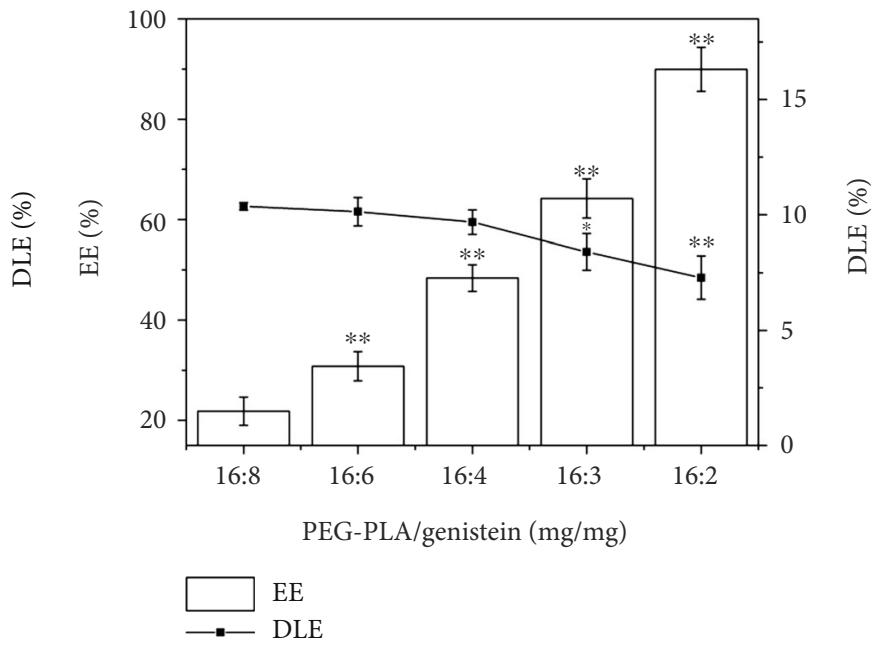

(d)

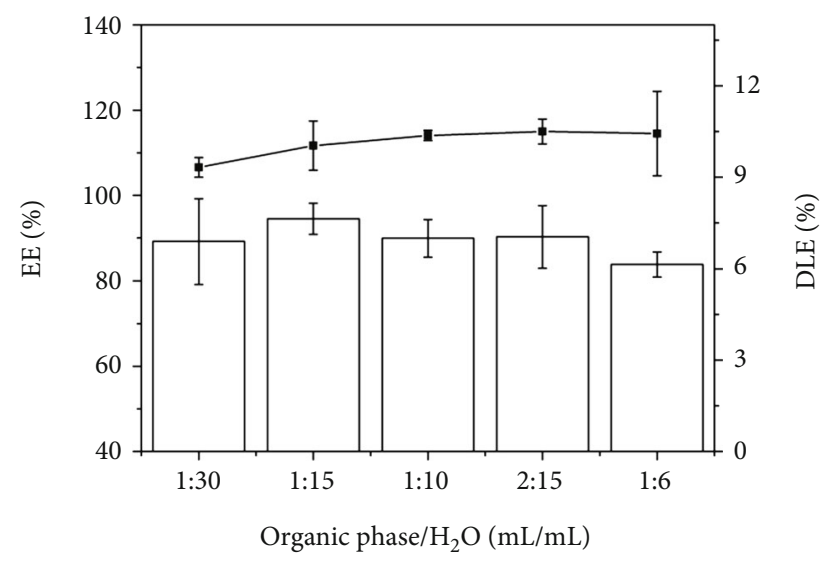

EE

DLE

(e)

FIGURE 4: Effects of polyvinyl alcohol (PVA) concentration (a), Tween 80 concentration (b), sonication time (c), PEG-PLA/genistein ratio (d), and organic $/ \mathrm{H}_{2} \mathrm{O}$ ratio (e) on the encapsulation efficiency (EE) and drug loading efficiency (DLE) of genistein micelles $(n=3$, mean $\pm \mathrm{SD}$, ${ }^{*} P<0.05,{ }^{* *} P<0.01$ compared with the first time point). 


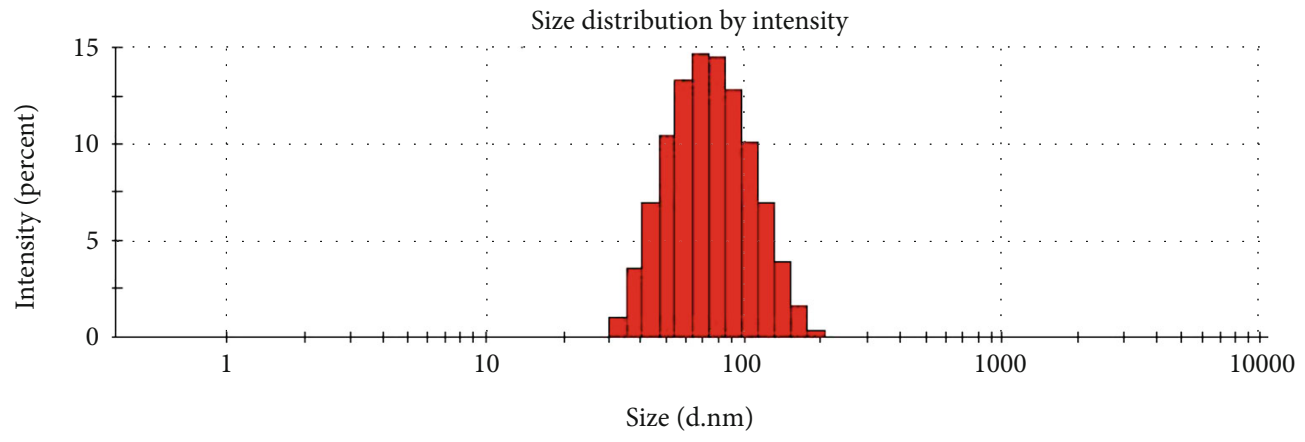

(a)

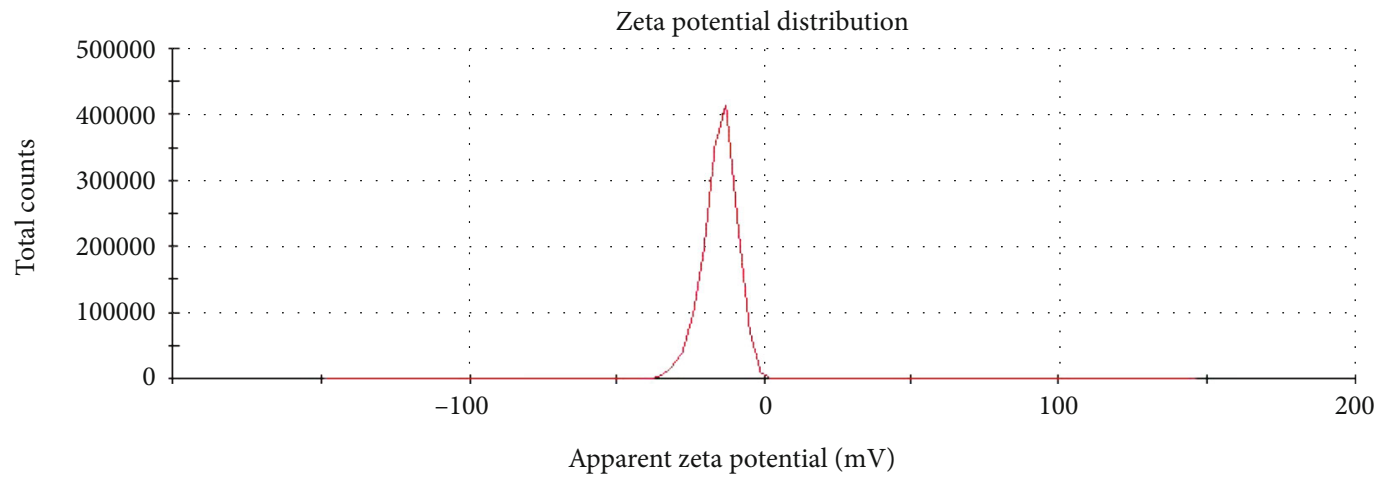

(b)

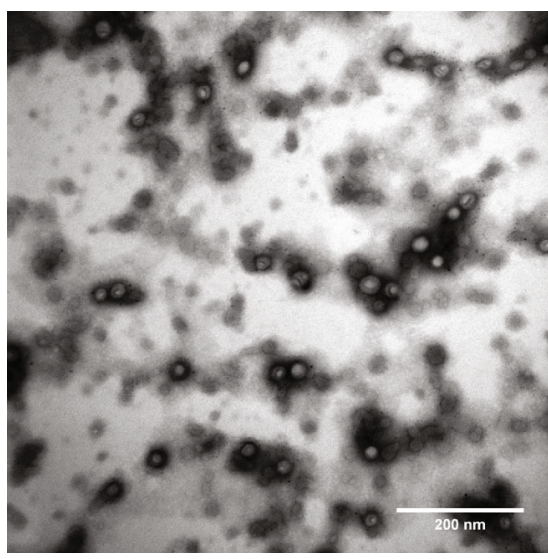

(c)

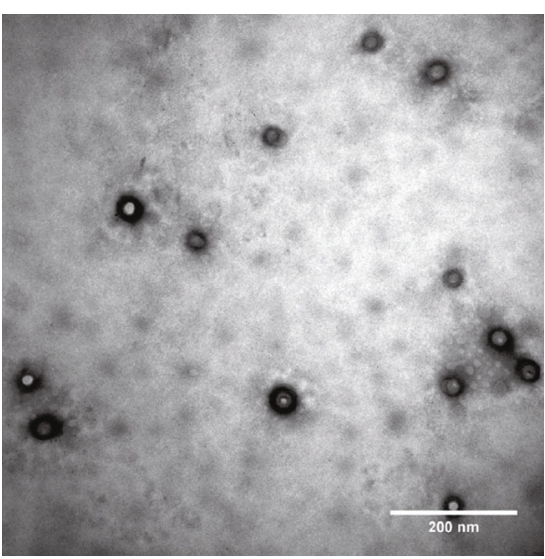

(d)

Figure 5: Characterization of genistein micelles (GMs). (a) Particle size distribution of GMs. (b) Zeta potential of GMs. (c) Morphology of blank micelles on transmission electron microscopy (TEM). (d) Morphology of GMs on TEM.

higher ratio decreased DLE and increased EE (Figure 4(d)), indicating that genistein was a rate-limiting factor for DLE and EE. Moreover, different organic (acetone) $/ \mathrm{H}_{2} \mathrm{O}$ ratios had no significant impact on the micellar diameter, $\mathrm{EE}$, and DLE (Figures 3(e) and 4(e)). Under the experimental conditions of this study, PDI was lower than 0.3 , indicating that the micellar size was homogeneous. No individual parameter seemed to have any significant influence on PDI.

Based on these data, new batches of GMs were synthesized using the optimized parameters (Tween 80 concentration of $2.75 \mathrm{mg} / \mathrm{mL}$, PEG-PLA/genistein ratio of $16: 2$, no PVA, and no sonication). GMs had an average diameter of $68.58 \pm 1.32 \mathrm{~nm}$ (Figure 5(a)), PDI of $0.12 \pm 0.01$, zeta poten- tial of $-15.12 \pm 0.78 \mathrm{mV}$ (Figure 5(b)), EE of $95.74 \pm 3.20 \%$, and DLE of $10.63 \pm 0.36 \%$. The concentration of genistein in micelles was $79.78 \mu \mathrm{g} / \mathrm{mL}$, and solubility was 55.79 times higher than that of genistein dissolved in water.

TEM showed that GMs had a relatively homogeneous morphology, with an electronically less dense core presumably loaded with genistein molecules (Figures 5(c) and 5(d)). The average GM diameter on TEM was consistent with that found on Zetasizer Nano ZS90 (approximately $60 \mathrm{~nm}$ ). BMs and GMs appeared as fluffy hollow structures on TEM.

3.3. Characterization of GLP. For long-term storage, GMs were lyophilized by freeze drying with $10 \%(v / v)$ trehalose. 


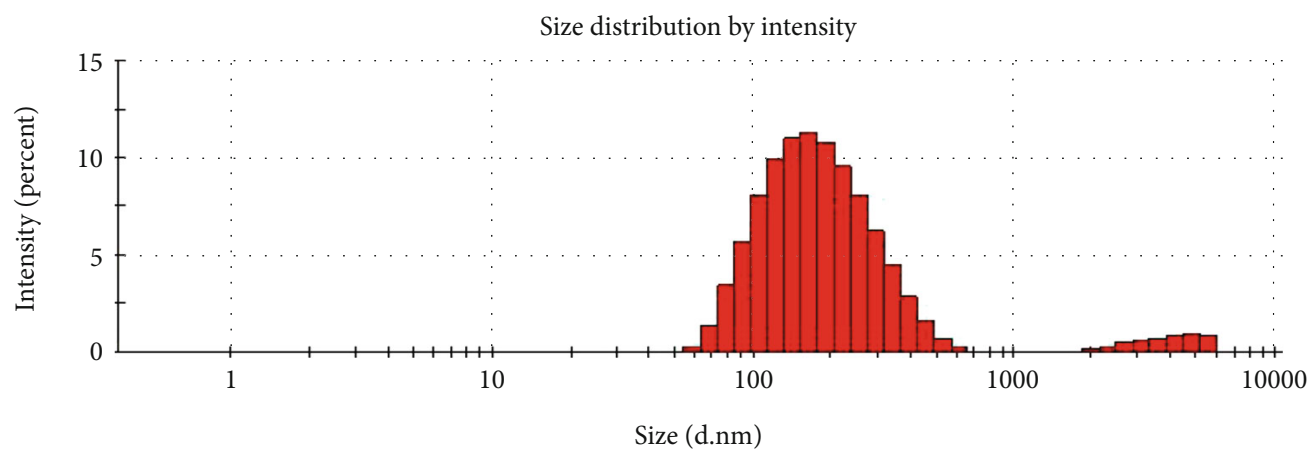

(a)

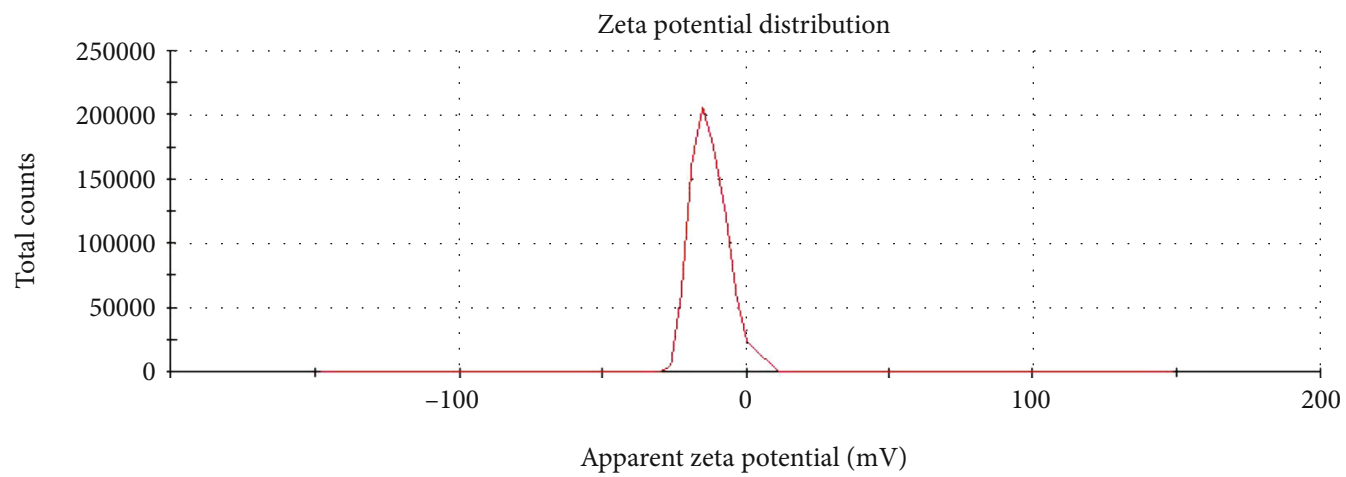

(b)

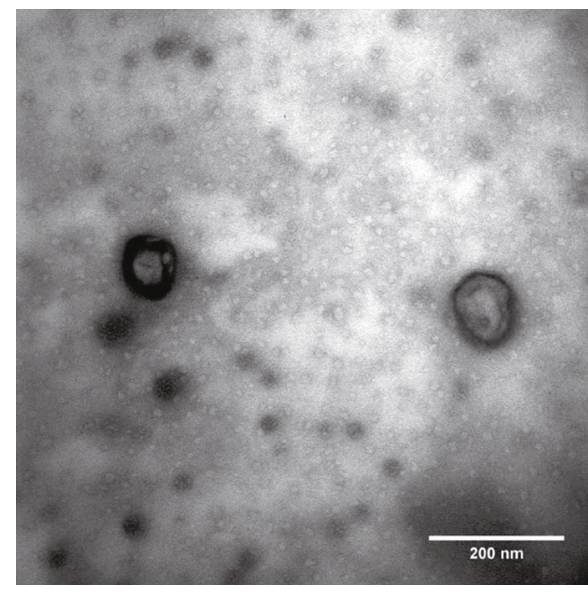

(c)

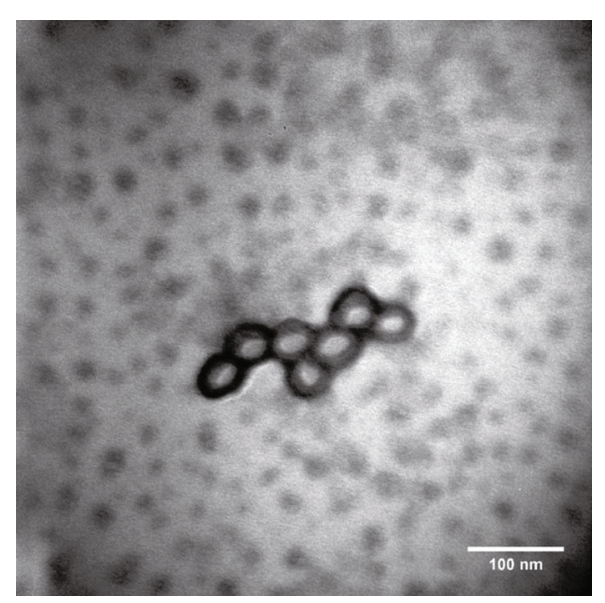

(d)

Figure 6: Characterization of genistein lyophilized powder (GLP). (a) Size distribution of GLP. (b) Zeta potential of GLP. (c) Morphology of blank lyophilized nanoparticles on transmission electron microscopy (TEM). (d) Morphology of GLP on TEM.

Trehalose was selected as a cryoprotectant for freeze drying to prevent micelles from coalescing and improve powder solubilization in water. GMs without this cryoprotectant coalesced during freeze drying and did not dissolve in water.

The average size, PDI, and zeta potential of watersuspended GLP was $163.30 \pm 0.70 \mathrm{~nm}$ (Figure 6(a)), $0.26 \pm$ 0.0095 , and $-12.10 \pm 0.53 \mathrm{mV}$, respectively (Figure 6(b)) The micellar structure of water-suspended BLP and GLP appeared to be intact under TEM (Figures 6(c) and 6(d)).

We next assessed GLP solubility in water at room temperature (Figure 7). GLP lyophilized from $2 \mathrm{~mL}$ of GMs in the leftmost vial (Figure 7(a)) was completely dissolved in $0.2 \mathrm{~mL}$ of DDW, showing a slightly blue color, and genis- tein concentration $(797.80 \mu \mathrm{g} / \mathrm{mL})$ was 556.90 times higher than that of genistein dissolved in water $(1.43 \mu \mathrm{g} / \mathrm{mL})$.

The FTIR spectra of genistein, BLP, GLP, and genistein+BLP are shown in Figure 8 . The major characteristic peaks of genistein were $840.38 \mathrm{~cm}^{-1}$ (benzene ring $\mathrm{C}-\mathrm{H}$ flexural vibration), $1204.18 \mathrm{~cm}^{-1}$ (C-O stretching vibration), $1519.72 \mathrm{~cm}^{-1}$ and $1615.11 \mathrm{~cm}^{-1}$ (benzene ring skeletal vibration), and $1652.12 \mathrm{~cm}^{-1}(\mathrm{C}=\mathrm{O}$ stretching vibration). The absorption peaks at $840 \mathrm{~cm}^{-1}$ (C-C stretching vibration), $1200 \mathrm{~cm}^{-1}$ (C-O stretching vibration), and $1650 \mathrm{~cm}^{-1}(\mathrm{C}=\mathrm{O}$ stretching vibration) can be attributed to the presence of PEG-PLA, trehalose, and Tween 80 in BLP, GLP, and genistein + BLP. 


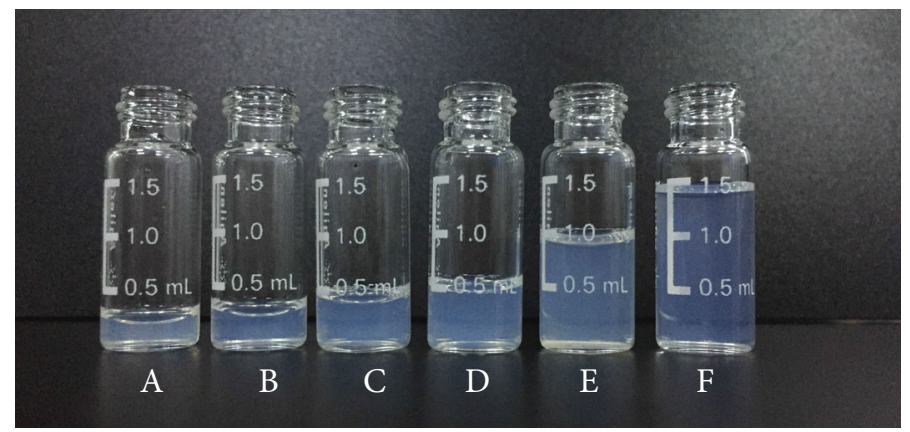

FIGURE 7: Solubility of genistein lyophilized powder (GLP). GLP lyophilized from $2 \mathrm{~mL}$ of genistein micelles was dissolved in $0.2 \mathrm{~mL}$ (a), $0.3 \mathrm{~mL}$ (b), $0.4 \mathrm{~mL}$ (c), $0.5 \mathrm{~mL}$ (d), $1.0 \mathrm{~mL}$ (e), and $1.5 \mathrm{~mL}$ (f) of water, respectively.

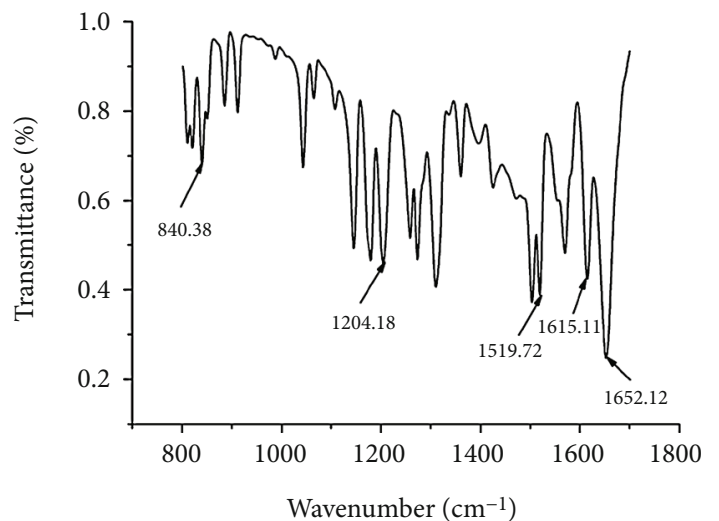

(a)

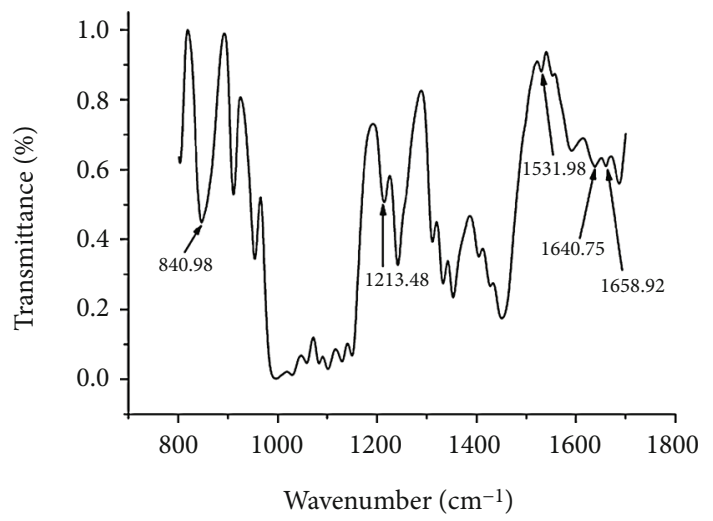

(c)

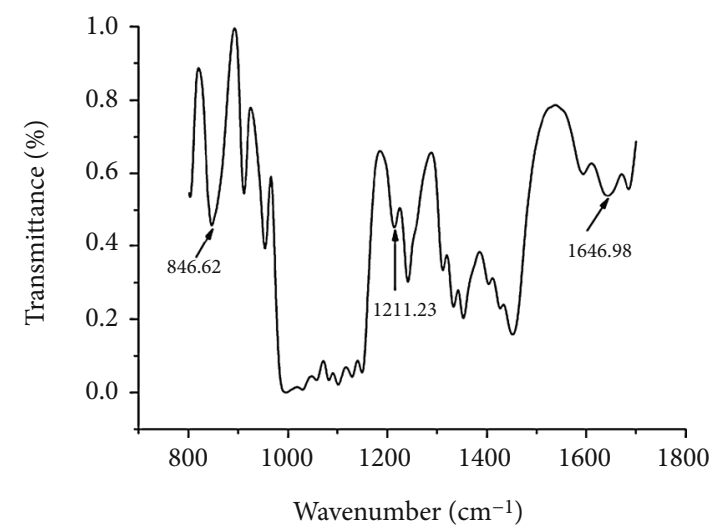

(b)

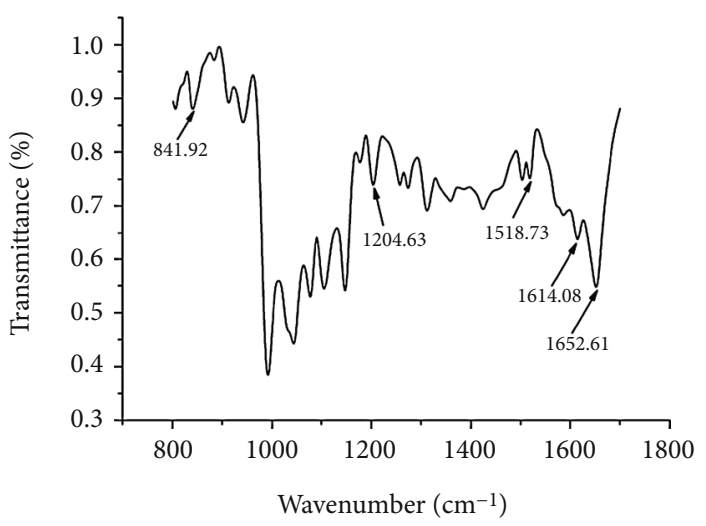

(d)

FIGURE 8: FTIR spectra of (a) genistein, (b) blank lyophilized powder (BLP), (c) genistein lyophilized powder, and (d) genistein + BLP.

For BLP, the peaks at $846.62 \mathrm{~cm}^{-1}$ (C-C stretching vibration), $1211.23 \mathrm{~cm}^{-1}$ (C-O stretching vibration), and $1646.98 \mathrm{~cm}^{-1}(\mathrm{C}=\mathrm{O}$ stretching vibration) correspond to the structural vibration of PEG-PLA, trehalose, and Tween 80 , respectively. In GLP spectra, the peak at $840.98 \mathrm{~cm}^{-1}$ may correspond to $\mathrm{C}-\mathrm{C}$ stretching vibration in PEG-PLA, trehalose, or Tween 80 , or benzene ring $\mathrm{C}-\mathrm{H}$ flexural vibration in genistein; $1213.48 \mathrm{~cm}^{-1}$ was due to $\mathrm{C}-\mathrm{O}$ stretching vibration in PEG-PLA, trehalose, and genistein; $1531.39 \mathrm{~cm}^{-1}$ and $1640.75 \mathrm{~cm}^{-1}$ may be derived from benzene ring skeletal vibration in genistein; and the absorption peak at $1658.92 \mathrm{~cm}^{-1}$ may originate from $\mathrm{C}=\mathrm{O}$ stretching vibration in PEG-PLA, trehalose, Tween 80 , and genistein. In genistein+BLP spectra, the peak at $841.92 \mathrm{~cm}^{-1}$ may be due to $\mathrm{C}-\mathrm{C}$ stretching vibration in PEG-PLA, trehalose, and Tween 80 ; and $841.92 \mathrm{~cm}^{-1}$ may originate from a benzene ring $\mathrm{C}-\mathrm{H}$ flexural vibration in genistein; $1204.63 \mathrm{~cm}^{-1}$ was derived from C-O stretching vibration in PEG-PLA, trehalose, Tween 80, and genistein; $1518.73 \mathrm{~cm}^{-1}$ and $1614.08 \mathrm{~cm}^{-1}$ can be attributed to benzene ring skeletal vibration in genistein; and $1652.61 \mathrm{~cm}^{-1}$ may be derived from $\mathrm{C}=\mathrm{O}$ stretching vibration in PEG-PLA, trehalose, and genistein. 


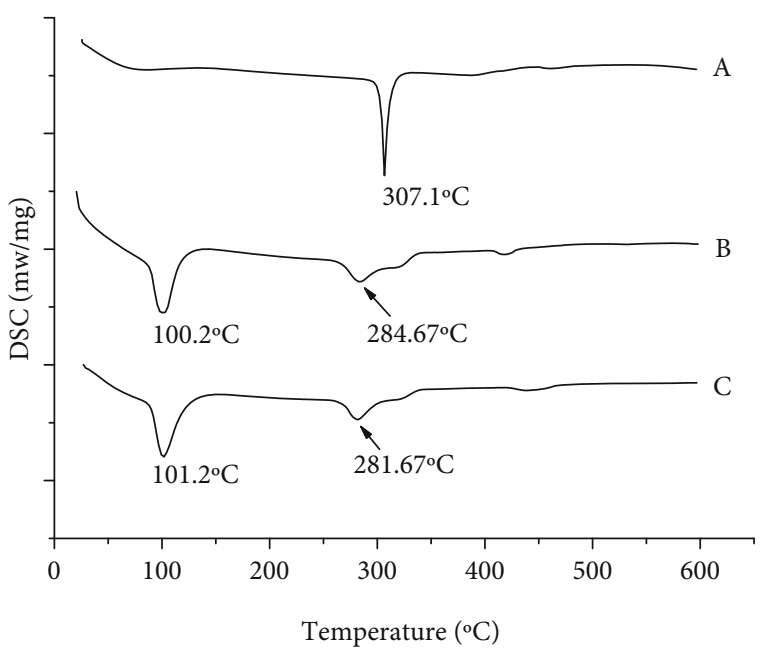

FIGURE 9: Analysis of (a) genistein, (b) blank lyophilized powder, and (c) genistein lyophilized powder by differential scanning calorimetry.

In GLP spectra, the absorption peak of benzene ring skeletal vibration in genistein, $1519.72 \mathrm{~cm}^{-1}$, may be shifted to $1531.39 \mathrm{~cm}^{-1}$, and $1615.11 \mathrm{~cm}^{-1}$ may be shifted to $1640.75 \mathrm{~cm}^{-1}$. The other characteristic peaks of genistein, $840 \mathrm{~cm}^{-1}, 1200 \mathrm{~cm}^{-1}$, and $1650 \mathrm{~cm}^{-1}$, may disappear or overlap with those of PEG-PLA and trehalose after encapsulating genistein into PEG-PLA scaffolds. These absorption shifts suggest that genistein may have been successfully incorporated into the micellar structure.

DSC was performed on genistein, BLP, and GLP to obtain dynamic thermal signatures (Figure 9). An endothermic peak for genistein was observed at $307.1^{\circ} \mathrm{C}$, indicating the presence of genistein (Figure 9(a)). A BLP signature consisted of a first endothermic peak at $100.2^{\circ} \mathrm{C}$ and a second endothermic peak at $284.67^{\circ} \mathrm{C}$ (Figure 9(b)). The DSC signature for GLP had a first peak at $101.2^{\circ} \mathrm{C}$ and a second peak at $281.67^{\circ} \mathrm{C}$. It is of note that the endothermic peak at $307.1^{\circ} \mathrm{C}$ for genistein was not found in GLP (Figure 9(c)), indicating the amorphous state of genistein in GLP [11].

3.4. Release of Genistein In Vitro. A solubility study was conducted to select an appropriate aqueous medium for the in vitro release of genistein. The solubility of genistein was improved by Tween 80 (Table 2). According to the sink conditions, the required volume of medium was two to four times lower than that required for drug saturation, and the required medium volume for drug release was calculated. PBS containing $2.75 \mathrm{mg} / \mathrm{mL}$ Tween 80 was selected as the aqueous medium to reduce methodological errors.

The release profile of genistein from GLP was determined using genistein as a control in a dialysis buffer containing $150 \mathrm{~mL}$ of PBS and Tween $80(2.75 \mathrm{mg} / \mathrm{mL})$ at $37^{\circ} \mathrm{C}$ with shaking at $100 \mathrm{rpm}$. The concentration of genistein in the medium increased over time, indicating its continuous release from GLP and the control sample; however, the release from GLP was faster (Figure 10). At $24 \mathrm{~h}$ and $48 \mathrm{~h}$, $93.76 \%$ and $100 \%$ of genistein was released from GLP, respectively, vs. $28.76 \%$ and $42.10 \%$ of genistein from the control sample, respectively. At $72 \mathrm{~h}, 55.69 \%$ of genistein was released from the control sample. The half-life of the control sample and GLP at $37^{\circ} \mathrm{C}$ was approximately $70 \mathrm{~h}$ and $5 \mathrm{~h}$, respectively. These results demonstrate that encapsulated genistein is readily released from nanoparticles, and the incorporation of hydrophobic genistein into PEG-PLA copolymers significantly improved its solubility and bioavailability.

The release profiles were fitted using different model equations, including zero order, first order, and Higuchi, and the regression coefficient $\left(r^{2}\right)$ was calculated (Table 3 ). The profiles followed first-order kinetics.

3.5. Effect of GLP on Cell Viability. The effect of BLP, genistein, and GLP (as equivalents of genistein concentration) on the viability of HSC-T6 cells was evaluated using the MTT assay. Treatment with genistein or GLP at concentrations lower than $20 \mu \mathrm{g} / \mathrm{mL}$ for $24 \mathrm{~h}$ did not significantly affect cell viability, whereas genistein or GLP at $80 \mu \mathrm{g} / \mathrm{mL}$ for $24 \mathrm{~h}$ reduced cell viability significantly (Table 4 ). At $48 \mathrm{~h}$, the toxicity of GLP at 40 and $80 \mu \mathrm{g} / \mathrm{mL}$ was significant (Table 5). At $72 \mathrm{~h}$, genistein was toxic to these cells, whereas the minimum GLP concentration that caused toxicity was $40 \mu \mathrm{g} / \mathrm{mL}$ (Table 6). BLP did not significantly inhibit the growth of HSC-T6 cells at concentrations higher than $80 \mu \mathrm{g} / \mathrm{mL}$ and treatment periods longer than $72 \mathrm{~h}$.

Treatment with $40-80 \mu \mathrm{g} / \mathrm{mL}$ of GLP for $24 \mathrm{~h}$ significantly decreased cell viability. Moreover, $40-80 \mu \mathrm{g} / \mathrm{mL}$ of GLP affected viability more strongly than $40 \mu \mathrm{g} / \mathrm{mL}$ of genistein. Treatment with $1.25-80 \mu \mathrm{g} / \mathrm{mL}$ of genistein for $48 \mathrm{~h}$, $2.5-80 \mu \mathrm{g} / \mathrm{mL}$ of GLP for $48 \mathrm{~h}$, or $5-80 \mu \mathrm{g} / \mathrm{mL}$ of genistein or GLP for $72 \mathrm{~h}$ significantly reduced cell viability.

The IC50 values of GLP at $24 \mathrm{~h}, 48 \mathrm{~h}$, and $72 \mathrm{~h}$ after treatment were $22.23,11.58$, and $7.48 \mu \mathrm{g} / \mathrm{mL}$, respectively, whereas the IC50 values of genistein were 52.46, 14.13, and $8.35 \mu \mathrm{g} / \mathrm{mL}$, respectively (Tables 5 and 6 ).

Based on these results, subsequent experiments were performed at a concentration ranging from 0 to $20 \mu \mathrm{g} / \mathrm{mL}$ and a treatment period of $48 \mathrm{~h}$.

3.6. Effects of GLP on HSC-T6 Cell Activation. We evaluated the effect of BLP, genistein, and GLP on the transcription of $\alpha$-SMA (a representative fibrotic marker) and collagen I in HSC-T6 cells. GLP at $10-20 \mu \mathrm{g} / \mathrm{mL}$ significantly decreased the mRNA expression of these genes, whereas $20 \mu \mathrm{g} / \mathrm{mL}$ of genistein suppressed the transcription of collagen I. BLP at $20 \mu \mathrm{g} / \mathrm{mL}$ slightly inhibited the transcription of these genes, which could be due to the presence of trehalose in this formulation; however, no current evidence substantiates this hypothesis. GLP at 10 and $20 \mu \mathrm{g} / \mathrm{mL}$ (especially $20 \mu \mathrm{g} / \mathrm{mL}$ ) suppressed gene expression more strongly than the corresponding concentrations of genistein (Table 7).

Western blotting showed that GLP decreased the protein expression of $\alpha$-SMA more strongly than the corresponding concentrations of BLP in HSC-T6 cells treated for $48 \mathrm{~h}$ (Table 8). 
TABLE 2: Solubility of genistein in different media and the medium volume required for drug release.

\begin{tabular}{lcr}
\hline Medium & Drug solubility $\left(\times 10^{-3} \mathrm{mg} / \mathrm{mL}\right)$ & Medium volume $(\mathrm{mL})$ \\
\hline PBS & 0 & $\infty$ \\
PBS containing $2.75 \mathrm{mg} / \mathrm{mL}$ Tween 80 & $46.40 \pm 4.15$ & $96.98-161.64$ \\
PBS containing $27.5 \mathrm{mg} / \mathrm{mL}$ Tween 80 & $273.20 \pm 38.15$ & $16.47-27.45$ \\
\hline
\end{tabular}

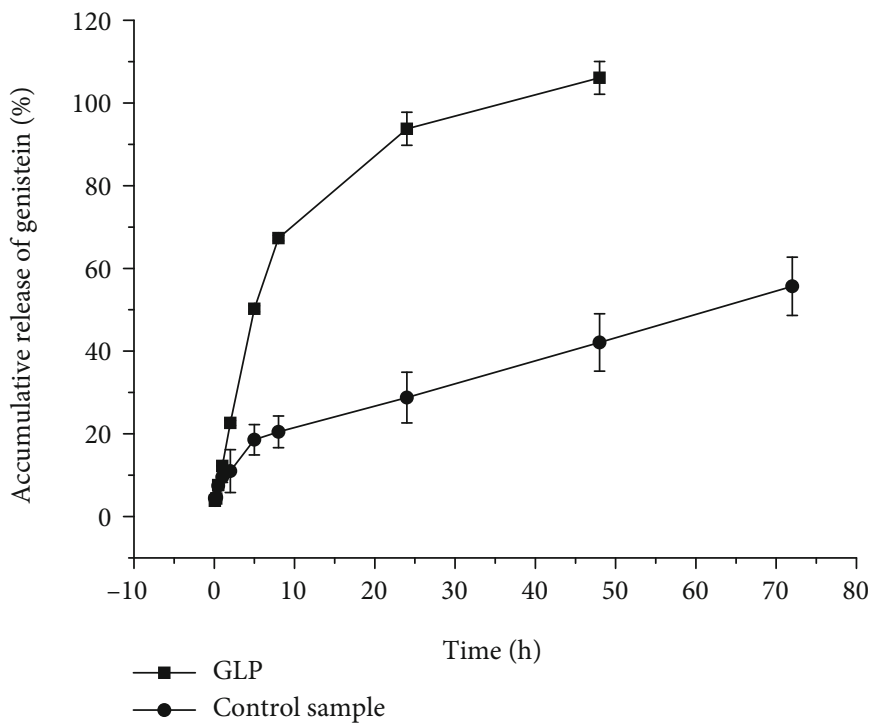

FIgURE 10: Time-dependent release of genistein lyophilized powder and control sample.

TABLE 3: Model fitting and calculation of the regression coefficient $\left(r^{2}\right)$ for determining the drug release profile.

\begin{tabular}{lcccccc}
\hline & \multicolumn{2}{c}{ Zero order } & \multicolumn{2}{c}{ First order } & \multicolumn{2}{c}{ Higuchi } \\
& $r^{2}$ & $Q=K_{0} t$ & $r^{2}$ & $\ln (100-Q)=-K t+C$ & $r^{2}$ & $Q=K_{H} t^{1 / 2}$ \\
\hline GLP & 0.7108 & $Q=6.8452 t$ & 0.9940 & $\ln (100-Q)=-0.1158 t+4.5537$ & 0.8611 & $Q=15.436 t^{1 / 2}$ \\
Control sample & 0.7220 & $C=0.8597 t$ & 0.9745 & $\ln (100-Q)=-0.0099 t+4.513$ & 0.8752 & $Q=10.398 t^{1 / 2}$ \\
\hline
\end{tabular}

GLP: genistein lyophilized powder; $Q$ : fractional release of the drug in time $t$; $k$ : rate constant; $C$ : constant.

\section{Discussion}

The beneficial effects of genistein are limited by its poor solubility in water and low bioavailability. In recent years, efforts have been made to utilize nanotechnology to improve drug bioavailability. For instance, methoxy poly(ethylene glycol)-block-( $\varepsilon$-caprolactone), methoxy PEG-PCL, and medium-chain triglycerides (MCT) were used to synthesize micellar emulsions containing genistein and improved its stability [31]. Self-emulsifying phospholipid preconcentrates improved the solubility and intestinal absorption of genistein [3]. A nanosuspension of genistein attenuated lung fibrosis induced by high-dose radiation exposure in a C57L/J murine model [39]. Furthermore, MPEG-b-PAE-g-HA GMs are used for treating ocular diseases [40]. In this study, we described a simple method for efficiently encapsulating genistein using PEG-PLA copolymers, and the obtained DLE was high. Hydrophobic genistein interacts with hydrophobic PLA and self-assembles into a micellar structure, such that hydrophilic PEG and genistein remain in the micelle periphery and core, respectively. Acetone was chosen as a solvent in the emulsion-evaporation method because the solubility of amphiphilic PEG-PLA and genistein was higher in acetone than in water. Genistein and PEG-PLA in acetone were immediately changed from an emulsion state to a micellar state since acetone is highly miscible with water, and micelles rapidly diffused into the aqueous phase. Autoclaving maintained the uniformity and stability of GMs for at least 7 days at $4^{\circ} \mathrm{C}$.

GMs were synthesized using PEG-PLA and a modified emulsion-evaporation method. GMs had a mean diameter of $68.58 \pm 1.32 \mathrm{~nm}, \mathrm{EE}$ of $95.74 \pm 3.20 \%$, and DLE of 10.63 $\pm 0.36 \%$. Higher concentrations of Tween 80 produced smaller micelles and higher DLE and EE. GMs were previously synthesized using polyoxyl 15-hydroxystearate combined with Pluronic F127 or Pluronic L61, yielding an EE of $80.79 \pm 0.55 \%$ and DLE of $1.69 \pm 0.24 \%$ or an EE of $83.40 \pm 1.36 \%$ and DLE of $2.26 \pm 0.18 \%$, respectively [41] 
TABLE 4: Viability of HSC-T6 cells treated with blank lyophilized powder (BLP), genistein, or genistein lyophilized powder (GLP) for $24 \mathrm{~h}$.

\begin{tabular}{|c|c|c|c|}
\hline $\begin{array}{l}\text { Concentration } \\
(\mu \mathrm{g} / \mathrm{mL})\end{array}$ & BLP & Genistein & GLP \\
\hline 0.3125 & $103.03 \pm 9.88$ & $94.82 \pm 16.64$ & $105.36 \pm 4.26$ \\
\hline 0.625 & $106.28 \pm 5.42$ & $95.14 \pm 6.70$ & $100.31 \pm 3.65$ \\
\hline 1.25 & $96.94 \pm 4.36$ & $93.03 \pm 11.44$ & $87.91 \pm 6.69$ \\
\hline 2.5 & $93.96 \pm 6.05$ & $83.74 \pm 19.63$ & $77.50 \pm 7.97$ \\
\hline 5 & $86.09 \pm 2.18$ & $85.70 \pm 22.35$ & $75.34 \pm 7.79$ \\
\hline 10 & $85.15 \pm 8.39$ & $82.47 \pm 20.55$ & $74.81 \pm 11.07$ \\
\hline 20 & $78.01 \pm 10.26$ & $71.61 \pm 14.63$ & $55.86 \pm 16.02$ \\
\hline 40 & $73.50 \pm 11.02$ & $54.34 \pm 11.60$ & $\underset{\Delta \Delta \# \#}{11.66 \pm 6.15}$ \\
\hline 80 & $70.10 \pm 7.05$ & $38.52 \pm 20.61^{* *}$ & $7.41 \pm 4.33^{\# \# *}$ \\
\hline \multicolumn{4}{|c|}{$\begin{array}{l}{ }^{*} P<0.05,{ }^{* *} P<0.01 \text { compared with untreated cells. }{ }^{*} P<0.05,{ }^{\#} P<0.01 \\
\text { compared with BLP-treated cells. }{ }^{\star} P<0.05, \triangle \triangle P<0.01 \text { compared with } \\
\text { genistein-treated cells. Data are representative of six independent } \\
\text { experiments. }\end{array}$} \\
\hline \multicolumn{4}{|c|}{$\begin{array}{l}\text { TABLE 5: Viability of HSC-T6 cells treated with blank lyophilized } \\
\text { powder (BLP), genistein, or genistein lyophilized powder (GLP) } \\
\text { for } 48 \mathrm{~h} \text {. }\end{array}$} \\
\hline $\begin{array}{l}\text { Concentration } \\
(\mu \mathrm{g} / \mathrm{mL})\end{array}$ & BLP & Genistein & GLP \\
\hline 0.3125 & $99.67 \pm 5.11$ & $97.67 \pm 6.54$ & $103.44 \pm 1.80$ \\
\hline 0.625 & $101.87 \pm 1.78$ & $92.67 \pm 4.76$ & $98.59 \pm 6.37$ \\
\hline 1.25 & $97.05 \pm 2.61$ & $85.69 \pm 1.09^{\#}$ & $91.65 \pm 8.82$ \\
\hline 2.5 & $96.48 \pm 3.18$ & $83.50 \pm 5.10^{\#}$ & $78.26 \pm 4.84^{\# \#}$ \\
\hline 5 & $93.64 \pm 10.44$ & $74.81 \pm 3.13^{\#}$ & $66.83 \pm 4.26^{\# \#}$ \\
\hline 10 & $89.93 \pm 6.06$ & $63.91 \pm 3.64^{\# \#}$ & $60.51 \pm 7.02^{\# \#}$ \\
\hline 20 & $85.21 \pm 7.66$ & $40.40 \pm 6.40^{\# \#}$ & $28.75 \pm 11.23^{\# \#}$ \\
\hline 40 & $76.93 \pm 4.07 \quad 2$ & $23.71 \pm 7.98^{\# \# * *}$ & $3.79 \pm 1.00^{\# \# * *}$ \\
\hline 80 & $67.56 \pm 7.51$ & $13.69 \pm 4.89^{\# \# *}$ & $3.27 \pm 0.56^{\# \# * *}$ \\
\hline
\end{tabular}

${ }^{*} P<0.05,{ }^{* *} P<0.01$ compared with untreated cells. ${ }^{\#} P<0.05,{ }^{\#} P<0.01$ compared with BLP-treated cells. Data are representative of six independent experiments.

The EE and DLE of GMs prepared with Soluplus ${ }^{\circledR}$ and vitamin E D- $\alpha$-tocopheryl PEG 1000 succinate were 97.12 $\pm 2.11 \%$ and $3.87 \pm 1.26 \%$, respectively [41]. These results indicate that the method adopted in the present study produces GMs with higher DLE and EE. FTIR and DSC analyses demonstrated that the resulting nanoparticles possessed a micellar structure in which genistein molecules were encapsulated in the lipid core. GMs were efficiently released from GLP following first-order kinetics. FTIR and DSC were previously used to determine the interaction/complexation of ursolic acid with PLA matrix and drug amorphization promoted by nanoencapsulation [11].

PEG coating can greatly reduce GM uptake by the reticuloendothelial system, clearance from the blood, degradation by metabolic enzymes, and immunogenicity. Other studies
TABLE 6: Viability of HSC-T6 cells treated with blank lyophilized powder (BLP), genistein, or genistein lyophilized powder (GLP) for $72 \mathrm{~h}$.

\begin{tabular}{lccc}
\hline $\begin{array}{l}\text { Concentration } \\
(\mu \mathrm{g} / \mathrm{mL})\end{array}$ & BLP & Genistein & GLP \\
\hline 0.3125 & $99.57 \pm 4.81$ & $96.63 \pm 5.32$ & $96.22 \pm 1.91$ \\
0.625 & $97.07 \pm 5.82$ & $96.28 \pm 5.90$ & $94.05 \pm 11.01$ \\
1.25 & $93.84 \pm 4.25$ & $90.95 \pm 8.73$ & $91.01 \pm 8.39$ \\
2.5 & $98.30 \pm 2.05$ & $79.24 \pm 11.21$ & $81.32 \pm 7.72$ \\
5 & $94.55 \pm 2.54$ & $67.23 \pm 10.51^{\#}$ & $58.68 \pm 7.37^{\# \#}$ \\
10 & $90.50 \pm 2.26$ & $47.62 \pm 8.21^{\#}$ & $39.99 \pm 1.24^{\# \# * *}$ \\
20 & $78.70 \pm 8.83$ & $23.52 \pm 11.80$ & $11.17 \pm 7.70^{\# \#}$ \\
40 & $71.98 \pm 4.86$ & $8.23 \pm 5.05^{\# \# *}$ & $2.00 \pm 0.09^{\# \# * *}$ \\
80 & $60.68 \pm 3.81$ & $4.47 \pm 2.41^{\# \# *}$ & $1.53 \pm 0.73^{\# \# * *}$ \\
\hline
\end{tabular}

${ }^{*} P<0.05,{ }^{* *} P<0.01$ compared with untreated cells. ${ }^{\#} P<0.05,{ }^{\# \#} P<0.01$ compared with BLP-treated cells. Data are representative of six independent experiments.

used PEG, PLA, and PEG-PLA to successfully deliver drugs to the brain [16], oral cavity [42], and nasal cavity [43, 44]. In the present study, the solubility of genistein in water increased 55.79- and 556.90-fold after incorporation into micelles and encapsulation/freeze drying, respectively. Furthermore, $93.76 \%$ of genistein was released from GLP into the dialysis buffer in $24 \mathrm{~h}$. Self-emulsifying phospholipid preconcentrates have been shown to improve genistein solubility and intestinal absorption [3].

Trehalose is an efficient lyoprotectant and can be used in nanoparticle systems to increase the uptake and biological activity of drugs [45]. Trehalose inhibits the abnormal proliferation of human keratinocytes induced by UVB radiation and protects keratinocytes against virus infection by inducing autophagy [46], inhibits the proliferation of fibroblasts at a concentration of $5 \%$ in vivo and in vitro and the expression of vimentin and $\alpha$-SMA at higher concentrations [47], and suppresses the BAX gene in cattle ovarian granulosa celn in cultured HSCs. Nonetheless, additional in vivo studies using hepatic fibrosis models are necessary to assess the translational potential of GLP.

It is at concentrations higher than $0.2 \mathrm{~mol} / \mathrm{L}$ [48]. The overexpression of $\alpha$-SMA is a pathological hallmark of the activation of HSCs and their transition to myofibroblasts [49]. In this study, trehalose and genistein synergistically decreased the viability of HSC-T6 cells, and GLP inhibited $\alpha$-SMA transcription more strongly than genistein.

Genistein reduces the activation of HSCs by inhibiting tyrosine protein kinases $[50,51]$. Genistein promoted the proliferation of Caco2-BBe cells in vitro at a concentration $\leq 1 \mu \mathrm{g} / \mathrm{mL}$ but inhibited cell cycle progression and cell proliferation at 7$30 \mu \mathrm{g} / \mathrm{mL}$ [52]. Genistein at $10.8 \mu \mathrm{g} / \mathrm{mL}$ and $21.6 \mu \mathrm{g} / \mathrm{mL}$ suppressed the estradiol-stimulated growth of Caco- 2 cells by inactivating c-src, leading to the inactivation of MAP kinases [53]. In the present study, GLP at concentrations lower than $20 \mu \mathrm{g} / \mathrm{mL}$ (measured as equivalents of genistein) did not affect 
TABLE 7: Semiquantitative PCR analysis of the mRNA levels of $\alpha$-SMA and collagen I in HSC-T6 cells treated with blank lyophilized powder (BLP), genistein, or genistein lyophilized powder (GLP) for $48 \mathrm{~h}$.

\begin{tabular}{lcccr}
\hline Gene & Concentration $(\mu \mathrm{g} / \mathrm{mL})$ & BLP & Genistein & GLP \\
\hline \multirow{3}{*}{$\alpha$-SMA } & 5 & $0.99 \pm 0.07$ & $0.97 \pm 0.07$ & $0.94 \pm 0.01$ \\
& 10 & $0.94 \pm 0.07$ & $0.83 \pm 0.05$ & $0.56 \pm 0.01^{\Delta \# *}$ \\
& 20 & $0.86 \pm 0.05$ & $0.75 \pm 0.10$ & $0.11 \pm 0.01^{\Delta \Delta \# * *}$ \\
Collagen I & 5 & $1.00 \pm 0.04$ & $0.86 \pm 0.14$ & $0.97 \pm 0.10$ \\
& 10 & $0.98 \pm 0.11$ & $0.71 \pm 0.15$ & $0.66 \pm 0.03^{*}$ \\
& 20 & $0.84 \pm 0.06$ & $0.43 \pm 0.06^{\# \# * *}$ & $0.27 \pm 0.01^{\# \# * *}$ \\
\hline
\end{tabular}

Gene expression was normalized against the housekeeping gene GAPDH. Each column represents mean \pm S.D. $(n=3)$. ${ }^{*}, * *$ Significantly different at $5 \%$ and $1 \%$, respectively, compared with $0 \mu \mathrm{g} / \mathrm{mL}$; $\#$, \#\# significantly different at $5 \%$ and $1 \%$, respectively, compared with the same concentrations of BLP; ${ }^{\triangle,} \triangle \triangle$ significantly different at $5 \%$ and $1 \%$, respectively, compared with the same concentrations of genistein.

TABLE 8: Western blot analysis of the protein levels of $\alpha$-SMA in HSC-T6 cells treated with blank lyophilized powder (BLP), genistein, or genistein lyophilized powder (GLP) for $48 \mathrm{~h}$.

\begin{tabular}{lccc}
\hline Concentrations $(\mu \mathrm{g} / \mathrm{mL})$ & BLP & Genistein & GLP \\
\hline 5 & $0.96 \pm 0.14$ & $0.81 \pm 0.05$ & $0.72 \pm 0.10$ \\
10 & $0.92 \pm 0.14$ & $0.72 \pm 0.07$ & $0.55 \pm 0.06$ \\
20 & $0.77 \pm 0.08$ & $0.69 \pm 0.11$ & $0.45 \pm 0.11^{\#}$ \\
\hline
\end{tabular}

Gene expression was normalized against the housekeeping gene GAPDH. The experiments were performed independently three times, and data are mean \pm S.D. ${ }^{\#} P<0.05$ compared with BLP-treated cells.

the viability of HSC-T6 cells, and cellular toxicity was similar to that of genistein. Treatment with $20 \mu \mathrm{g} / \mathrm{mL}$ of BLP for $72 \mathrm{~h}$ did not affect cell viability, suggesting that the substances used to produce GLP were not cytotoxic. More importantly, GLP concentrations higher than $5 \mu \mathrm{g} / \mathrm{mL}$ retained the ability of genistein to suppress the activation and proliferation of HSCs in a timedependent and dose-dependent manner. On a molar basis, GLP was more potent than genistein in suppressing the activation and proliferation of HSCs.

The overexpression and accumulation of collagen $\mathrm{I}$ is a major pathological hallmarks of hepatic fibrosis and a therapeutic target [54]. The PCR results showed that GLP but not BLP inhibited the transcriptional expression of $\alpha$-SMA and collagen I and was more effective than genistein in suppressing the expression of collagen I on a molar basis. We hypothesize that genistein did not significantly affect the protein expression of $\alpha$-SMA because the treatment period was short.

\section{Conclusion}

This study demonstrated the proof of concept for improving the bioavailability and potency of genistein through encapsulation with PEG-PLA copolymers using a simple method. The safety and antifibrotic effects of GLP were proven.

\section{Data Availability}

The datasets used and/or analyzed in the current study are available from the corresponding author on reasonable request.

\section{Conflicts of Interest}

The authors declare no conflicts of interest.

\section{Authors' Contributions}

Qiuchen Cheng and Wen Qin contributed equally to this work.

\section{Acknowledgments}

This work was supported by the National Natural Science Foundation of China (Process No. 81460127), the Guangxi Science and Technology Cooperation and Exchange Program (Process No. 14123001-18), and the self-funded research project of the Guangxi Zhuang Autonomous Region Health and Family Planning Commission (Process Nos. Z20180266 and Z20180267).

\section{References}

[1] Y. L. Bi, M. Min, W. Shen, and Y. Liu, "Genistein induced anticancer effects on pancreatic cancer cell lines involves mitochondrial apoptosis, $G_{0} / G_{1}$ cell cycle arrest and regulation of STAT3 signalling pathway," Phytomedicine, vol. 39, pp. 1016, 2018.

[2] R. Boonpawa, A. Spenkelink, A. Punt, and I. Rietjens, "In vitroin silico-based analysis of the dose-dependent in vivo oestrogenicity of the soy phytoestrogen genistein in humans," British Journal of Pharmacology, vol. 174, no. 16, pp. 2739-2757, 2017.

[3] E. M. Shehata, Y. S. Elnaggar, S. Galal, and O. Y. Abdallah, "Self-emulsifying phospholipid pre-concentrates (SEPPs) for improved oral delivery of the anti-cancer genistein: development, appraisal and ex-vivo intestinal permeation," International Journal of Pharmaceutics, vol. 511, no. 2, pp. 745-756, 2016.

[4] P. Su, J. Zhang, S. Wang et al., "Genistein alleviates leadinduced neurotoxicity in vitro and in vivo: involvement of multiple signaling pathways," Neurotoxicology, vol. 53, pp. 153-164, 2016.

[5] F. Yuan-Jing, W. Wei, L. Jian-Ping, J. Yu-Xia, and D. Zi-Ling, "Genistein promotes the metabolic transformation of acetaminophen to glucuronic acid in human L-O2, HepG2 and 
Hep3b cells via the Nrf2/Keap1 pathway," Food \& Function, vol. 7, no. 11, pp. 4683-4692, 2016.

[6] X. Zhai, M. Lin, F. Zhang et al., "Dietary flavonoid genistein induces Nrf2 and phase II detoxification gene expression via ERKs and PKC pathways and protects against oxidative stress in Caco-2 cells," Molecular Nutrition \& Food Research, vol. 57, no. 2, pp. 249-259, 2013.

[7] J. T. Kim, S. Barua, H. Kim et al., "Absorption study of genistein using solid lipid microparticles and nanoparticles: control of oral bioavailability by particle sizes," Biomolecules \& Therapeutics, vol. 25, no. 4, pp. 452-459, 2017.

[8] C. Spagnuolo, G. L. Russo, I. E. Orhan et al., "Genistein and cancer: current status, challenges, and future directions," Advances in Nutrition, vol. 6, no. 4, pp. 408-419, 2015.

[9] J. Tang, N. Xu, H. Ji, H. Liu, Z. Wang, and L. Wu, "Eudragit nanoparticles containing genistein: formulation, development, and bioavailability assessment," International Journal of Nanomedicine, vol. 6, pp. 2429-2435, 2011.

[10] J.-G. Wu, J. Ge, Y.-P. Zhang, Y. Yu, and X.-Y. Zhang, "Solubility of genistein in water, methanol, ethanol, propan-2-ol, 1butanol, and ethyl acetate from (280 to 333) K," Journal of Chemical \& Engineering Data, vol. 55, no. 11, pp. 5286-5288, 2010.

[11] E. Antônio, O. D. R. J. Antunes, I. S. de Araújo, N. M. Khalil, and R. M. Mainardes, "Poly(lactic acid) nanoparticles loaded with ursolic acid: characterization and in vitro evaluation of radical scavenging activity and cytotoxicity," Materials Science and Engineering: C, vol. 71, pp. 156-166, 2017.

[12] P. Couvreur, B. Kante, M. Roland, P. Guiot, P. BAuduin, and P. Speiser, "Polycyanoacrylate nanocapsules as potential lysosomotropic carriers: preparation, morphological and sorptive properties," The Journal of Pharmacy and Pharmacology, vol. 31, no. 1, pp. 331-332, 1979.

[13] M. Li, M. Gao, Y. Fu et al., "Acetal-linked polymeric prodrug micelles for enhanced curcumin delivery," Colloids and Surfaces B: Biointerfaces, vol. 140, pp. 11-18, 2016.

[14] C. R. Lopes de Azambuja, L. G. dos Santos, M. R. Rodrigues et al., "Physico-chemical characterization of asolectingenistein liposomal system: an approach to analyze its in vitro antioxidant potential and effect in glioma cells viability," Chemistry and Physics of Lipids, vol. 193, pp. 24-35, 2015.

[15] D. Quintanar-Guerrero, D. Tamayo-Esquivel, A. GanemQuintanar, E. Allemann, and E. Doelker, "Adaptation and optimization of the emulsification-diffusion technique to prepare lipidic nanospheres," European Journal of Pharmaceutical Sciences, vol. 26, no. 2, pp. 211-218, 2005.

[16] H. Xia, X. Gao, G. Gu et al., "Penetratin-functionalized PEGPLA nanoparticles for brain drug delivery," International Journal of Pharmaceutics, vol. 436, no. 1-2, pp. 840-850, 2012.

[17] D. Cosco, D. Paolino, F. De Angelis et al., "Aqueous-core PEGcoated PLA nanocapsules for an efficient entrapment of water soluble anticancer drugs and a smart therapeutic response," European Journal of Pharmaceutics and Biopharmaceutics, vol. 89, pp. 30-39, 2015.

[18] H. Danafar, K. Rostamizadeh, S. Davaran, and M. Hamidi, "Drug-conjugated PLA-PEG-PLA copolymers: a novel approach for controlled delivery of hydrophilic drugs by micelle formation," Pharmaceutical Development and Technology, vol. 22, no. 8, pp. 947-957, 2017.

[19] Q. T. Phan, M. H. le, T. T. H. le, T. H. H. Tran, P. N. Xuan, and P. T. Ha, "Characteristics and cytotoxicity of folate-modified curcumin-loaded PLA-PEG micellar nano systems with various PLA:PEG ratios," International Journal of Pharmaceutics, vol. 507, no. 1-2, pp. 32-40, 2016.

[20] C. Garofalo, G. Capuano, R. Sottile et al., "Different insight into amphiphilic PEG-PLA copolymers: influence of macromolecular architecture on the micelle formation and cellular uptake," Biomacromolecules, vol. 15, no. 1, pp. 403-415, 2014.

[21] Y. Shi, W. Huang, R. Liang et al., "Improvement of in vivo efficacy of recombinant human erythropoietin by encapsulation in PEG-PLA micelle," International Journal of Nanomedicine, vol. 8, pp. 1-11, 2013.

[22] B. Tyler, D. Gullotti, A. Mangraviti, T. Utsuki, and H. Brem, "Polylactic acid (PLA) controlled delivery carriers for biomedical applications," Advanced Drug Delivery Reviews, vol. 107, pp. 163-175, 2016.

[23] H. Liang, J. M. Friedman, and P. Nacharaju, "Fabrication of biodegradable PEG-PLA nanospheres for solubility, stabilization, and delivery of curcumin," Artificial Cells, Nanomedicine, and Biotechnology, vol. 45, no. 2, pp. 297-304, 2017.

[24] R. Ghasemi, M. Abdollahi, E. Emamgholi Zadeh et al., "mPEG-PLA and PLA-PEG-PLA nanoparticles as new carriers for delivery of recombinant human growth hormone (rhGH)," Scientific Reports, vol. 8, no. 1, article 9854, 2018.

[25] W. Zou, C. Liu, Z. Chen, and N. Zhang, "Preparation and characterization of cationic PLA-PEG nanoparticles for delivery of plasmid DNA," Nanoscale Research Letters, vol. 4, no. 9, pp. 982-992, 2009.

[26] C. Zhang and L. Zhuo, "Epigallocatechin gallate and genistein attenuate glial fibrillary acidic protein elevation induced by fibrogenic cytokines in hepatic stellate cells," International Journal of Molecular Medicine, vol. 18, no. 6, pp. 1141-1151, 2006.

[27] T. Higashi, S. L. Friedman, and Y. Hoshida, "Hepatic stellate cells as key target in liver fibrosis," Advanced Drug Delivery Reviews, vol. 121, pp. 27-42, 2017.

[28] V. Krizhanovsky, M. Yon, R. A. Dickins et al., "Senescence of activated stellate cells limits liver fibrosis," Cell, vol. 134, no. 4, pp. 657-667, 2008.

[29] Z. Daman, H. Montazeri, M. Azizi et al., "Polymeric micelles of PEG-PLA copolymer as a carrier for salinomycin against gemcitabine-resistant pancreatic cancer," Pharmaceutical Research, vol. 32, no. 11, pp. 3756-3767, 2015.

[30] I. A. Siddiqui, V. M. Adhami, D. J. Bharali et al., "Introducing nanochemoprevention as a novel approach for cancer control: proof of principle with green tea polyphenol epigallocatechin3-gallate," Cancer Research, vol. 69, no. 5, pp. 1712-1716, 2009.

[31] T. Zhang, H. Wang, Y. Ye, X. Zhang, and B. Wu, "Micellar emulsions composed of $\mathrm{mPEG}-\mathrm{PCL} / \mathrm{MCT}$ as novel nanocarriers for systemic delivery of genistein: a comparative study with micelles," International Journal of Nanomedicine, vol. 10, no. 1, pp. 6175-6184, 2015.

[32] Q. Pan, J. Zhang, X. Li et al., "Preparation and pharmacokinetics of bifunctional epirubicin-loaded micelles," Die Pharmazie, vol. 74, no. 10, pp. 577-582, 2019.

[33] Y. Li, Y. Luo, X. Zhang, X. Lin, M. He, and M. Liao, "Combined taurine, epigallocatechin gallate and genistein therapy reduces HSC-T6 cell proliferation and modulates the expression of fibrogenic factors," International Journal of Molecular Sciences, vol. 14, no. 10, pp. 20543-20554, 2013.

[34] E. Montanari, M. C. De Rugeriis, C. Di Meo et al., "One-step formation and sterilization of gellan and hyaluronan 
nanohydrogels using autoclave," Journal of materials science Materials in medicine, vol. 26, no. 1, article 5362, 2015.

[35] H.-Y. Kwon, J.-Y. Lee, S.-W. Choi, Y. Jang, and J.-H. Kim, "Preparation of PLGA nanoparticles containing estrogen by emulsification-diffusion method," Colloids and Surfaces A: Physicochemical and Engineering Aspects, vol. 182, no. 1-3, pp. 123-130, 2001.

[36] O. Diou, S. Greco, T. Beltran, D. Lairez, J. R. Authelin, and D. Bazile, "A method to quantify the affinity of cabazitaxel for PLA-PEG nanoparticles and investigate the influence of the nano-assembly structure on the drug/particle association," Pharmaceutical Research, vol. 32, no. 10, pp. 3188-3200, 2015.

[37] X. Sha, J. Wu, Y. Chen, and X. Fang, "Self-microemulsifying drug-delivery system for improved oral bioavailability of probucol: preparation and evaluation," International Journal of Nanomedicine, vol. 7, pp. 705-712, 2012.

[38] E. Blanco, E. A. Bey, Y. Dong et al., "Beta-lapachone-containing PEG-PLA polymer micelles as novel nanotherapeutics against NQO1-overexpressing tumor cells," Journal of Controlled Release, vol. 122, no. 3, pp. 365-374, 2007.

[39] I. L. Jackson, A. Zodda, G. Gurung et al., "BIO 300, a nanosuspension of genistein, mitigates pneumonitis/fibrosis following high-dose radiation exposure in the C57L/J murine model," British Journal of Pharmacology, vol. 174, no. 24, pp. 47384750, 2017.

[40] C. Li, R. Chen, M. Xu, J. Qiao, L. Yan, and X. D. Guo, "Hyaluronic acid modified MPEG- $b$-PAE block copolymer aqueous micelles for efficient ophthalmic drug delivery of hydrophobic genistein,” Drug Delivery, vol. 25, no. 1, pp. 1258-1265, 2018.

[41] P. Ding, Y. Chen, G. Cao, H. Shen, J. Ju, and W. Li, "Solutol ${ }^{(\mathrm{R})} \mathrm{HS} 15+$ pluronicF127 and Solutol ${ }^{(\mathrm{R})} \mathrm{HS} 15$ +pluronicL61 mixed micelle systems for oral delivery of genistein," Drug Design, Development and Therapy, vol. 13, pp. 1947-1956, 2019.

[42] W. Yao, P. Xu, J. Zhao et al., "RGD functionalized polymeric nanoparticles targeting periodontitis epithelial cells for the enhanced treatment of periodontitis in dogs," Journal of Colloid and Interface Science, vol. 458, pp. 14-21, 2015.

[43] A. Vila, H. Gill, O. McCallion, and M. J. Alonso, "Transport of PLA-PEG particles across the nasal mucosa: effect of particle size and PEG coating density," Journal of Controlled Release, vol. 98, no. 2, pp. 231-244, 2004.

[44] A. Vila, A. Sánchez, C. Évora, I. Soriano, J. L. V. Jato, and M. J. Alonso, "PEG-PLA nanoparticles as carriers for nasal vaccine delivery," Journal of Aerosol Medicine, vol. 17, no. 2, pp. 174-185, 2004.

[45] A. J. Mukalel, B. C. Evans, K. V. Kilchrist et al., "Excipients for the lyoprotection of MAPKAP kinase 2 inhibitory peptide nano-polyplexes," Journal of Controlled Release, vol. 282, pp. 110-119, 2018.

[46] X. Chen, M. Li, L. Li et al., "Trehalose, sucrose and raffinose are novel activators of autophagy in human keratinocytes through an mTOR-independent pathway," Scientific reports, vol. 6, no. 1, article 28423, 2016.

[47] K. Takeuchi, M. Nakazawa, Y. Ebina et al., "Inhibitory effects of trehalose on fibroblast proliferation and implications for ocular surgery," Experimental Eye Research, vol. 91, no. 5, pp. 567-577, 2010.

[48] Y. X. Zheng, L. Z. Ma, S. J. Liu et al., "Protective effects of trehalose on frozen-thawed ovarian granulosa cells of cattle," Animal Reproduction Science, vol. 200, pp. 14-21, 2019.
[49] A. King, D. D. Houlihan, D. Kavanagh et al., "Sphingosine-1phosphate prevents egress of hematopoietic stem cells from liver to reduce fibrosis," Gastroenterology, vol. 153, no. 1, pp. 233-248.e16, 2017.

[50] B. M. Klinkhammer, J. Floege, and P. Boor, "PDGF in organ fibrosis," Molecular Aspects of Medicine, vol. 62, pp. 44-62, 2018.

[51] L. Zuo, Y. Zhu, L. Hu et al., "PI3-kinase/Akt pathwayregulated membrane transportation of acid-sensing ion channel $1 \mathrm{a} /$ calcium ion influx/endoplasmic reticulum stress activation on PDGF-induced HSC activation," Journal of Cellular and Molecular Medicine, vol. 23, no. 6, pp. 3940-3950, 2019.

[52] A. C. Chen and S. M. Donovan, "Genistein at a concentration present in soy infant formula inhibits Caco-2BBe cell proliferation by causing G2/M cell cycle arrest," The Journal of Nutrition, vol. 134, no. 6, pp. 1303-1308, 2004.

[53] M. Di Domenico, G. Castoria, A. Bilancio, A. Migliaccio, and F. Auricchio, "Estradiol activation of human colon carcinoma-derived Caco-2 cell growth," Cancer Research, vol. 56, no. 19, pp. 4516-4521, 1996.

[54] M. A. Karsdal, S. H. Nielsen, D. J. Leeming et al., "The good and the bad collagens of fibrosis - their role in signaling and organ function," Advanced Drug Delivery Reviews, vol. 121, pp. 43-56, 2017. 